\title{
Simultaneous thermal and contraction/ expansion curves analysis for solidification control of cast irons
}

\author{
*Iulian Riposan, Stelian Stan, Mihai Chisamera, Loredana Neacsu, Ana Maria Cojocaru, Eduard Stefan, \\ Iuliana Stan \\ Politehnica University of Bucharest, 313, Independentei Spl., 6th District, 060042 Bucharest, Romania
}

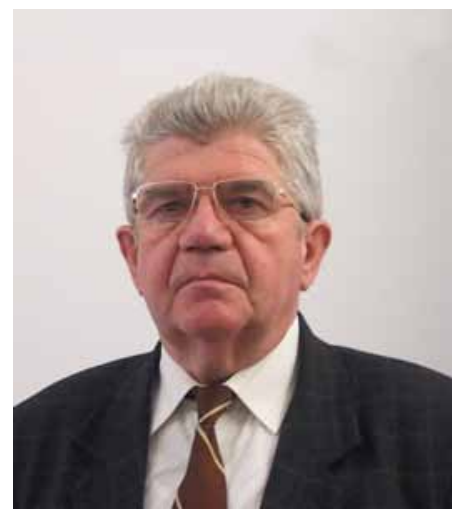

\section{*Iulian Riposan}

Born in 1948, Ph.D, Professor. His research interests mainly focus on processing and complex characterization of lamellar, nodular, compacted/vermicular and coral graphite irons, austempered cast irons with lamellar, nodular, compacted or coral graphite, cast iron matrix composites, cupola and electric furnaces operations. To date, he has published more than 300 technical papers and 3 technical books, and holds 35 patents. He is the honorary member of Technical Sciences Academy of Romania, the Past President of Romanian Foundry Technical Association (ATTR) (1996 - 2014), and an international member of American Foundry Society.

E-mail: iulian.riposan@upb.ro

Received: 2019-12-11

Accepted: 2020-01-21
Abstract: The first part of the paper summarizes the performance of two mould devices, illustrating by representative shrinkage tendency results in ductile cast iron as affected by mould rigidity (green and furan resin sand moulds) and inoculant type (FeSibased alloys). Less rigid green sand moulds encourage the formation of contraction defects, not only because of the high initial expansion values $\left(\varepsilon_{\mathrm{di}}\right)_{\max }$, but also because of the increased solidification undercooling. A high inoculation efficiency means not only lowering the carbides formation sensitivity and increasing the nodule count, but also a prolonged graphitization through to the end of the eutectic freezing, as observed by the high population of small late forming nodules, which leads to minimizing the tendency for shrinkage. The second part of the paper illustrates an application of this equipment to commercial foundry use. It conducts thermal analysis and volume change measurements in a single ceramic cup with cast iron quality as a variable. La-bearing FeSi inoculant appears to be more effective than RE (Rare Earth) -FeSi alloy in FeSiMgCa treated irons (no RE), in terms of reducing eutectic undercooling and $\left(\varepsilon_{\mathrm{di}}\right)_{\max }$, favourable for lower sensitivity to shrinkage formation. Experiments also compared solidification patterns for white [WI], grey [GI] and ductile [DI] irons, to correlate the most important events between the cooling curves and contraction curves, to evaluate the sensitivity to shrinkage formation. All of the irons have similar values for initial expansion up to the start of eutectic freezing, but, after that, the graphite formation promotes expansion (more than 5 times for nodular graphite), resulting in a difference in maximum expansion (2 times higher for DI). The graphitic expansion has two contrary effects. Increased graphitic expansion (force) leads to a higher shrinkage sensitivity during the first part of the eutectic reaction, but also to a decrease of shrinkage at the end of solidification, due to forcing the last liquid iron to occupy the previous formed cavities. Consequently, strong graphitization process promotion at the end of solidification favours the castings' soundness.

Key words: white, grey and ductile cast iron; solidification; undercooling; structure; simultaneous thermal and contraction analysis; graphite; graphitic expansion; shrinkage; inoculation

CLC numbers: TG143; Document code: A; Article ID: 1672-6421(2020) 02-096-15

$\mathrm{T}$ The final control of the iron castings' quality involves different techniques, including chemical analysis, microstructure evaluation, physical and mechanical properties measurements, castings' surface parameters and casting soundness control, etc. It is important to forecast the final castings' characteristics before mould filling, by iron melt solidification control, applying techniques able to illustrate the eutectic undercooling values referring to the stable and metastable equilibrium temperatures, carbide or graphite formation tendency, a specific graphite morphology occurrence, metal matrix make-up, shrinkage and microshrinkage sensitivity, etc.

Thermal (cooling curve) analysis has a wide application in the worldwide foundry industry to quickly control the solidification behaviour of foundry metallic alloys, especially for cast irons and non-ferrous alloys. At first, cooling curve analysis (CCA) 
was used in foundry shops to rapidly evaluate the carbon equivalent in cast irons and silicon content in Al-Si alloys, in both cases by identifying the change of the liquidus curve. Later, the first derivative of the cooling curve was added as a result of faster computer application in this field, and more precise measurements on the specific events on the cooling curve were possible. High quality information on the foundry floor within minutes of sampling is possible in this way, reducing the turnaround time of the laboratory to just a few minutes ${ }^{[1-3]}$.

For cast irons, some important parameters are found in this way, such as liquidus temperature (austenite or primary graphite formation start), the start temperature of eutectic freezing (nucleation), the lowest and the highest eutectic temperatures and temperature of the end of solidification. By comparing these events with equilibrium temperature in stable (graphitic) and metastable (carbidic) solidification systems, some important information can be obtained, such as carbide to graphite transition, eutectic recalescence level (important as shrinkage formation sensitivity), primary (solidification) structure qualitative parameters, efficiency of inoculation (graphitizing treatment), graphitizing potential, graphite morphology, sensitivity to inter-eutectic cells carbide or microshrinkage formation etc ${ }^{[1-12]}$.

Solidification and solid state cooling of the metallic castings up to room temperature is accompanied by contractionexpansion events, resulting in contraction or enlargement of final castings, comparing to the mould cavity sizes, depending on the melting-pouring procedure, nature of metallic materials, casting parameters and mould media characteristics. Shrinkage and micro-shrinkage formation is generally present in all metallic castings, but cast iron presents some peculiar behaviour. Specific for this material is the possibility of carbon to separate as carbide or/and graphite, at a large difference between their specific volume, and the possibility to form different graphite morphologies, which leads to different solidification patterns and contraction defects formation, respectively ${ }^{[11]}$.
Many research and foundry experiments were performed to find the most important influencing factors favourable for shrinkage and micro-shrinkage formation to avoid this frequent defect in metal castings production. In this respect, different factors were identified, such as the chemistry of a treated cast iron (Compositional factor $-\mathrm{C}+1 / 7 \mathrm{Si}, \mathrm{Mg}_{\text {res }}$, minor elements), mold features (rigidity/deformability, hardness stability), casting geometry (section modulus, feeding path), charge and melting practice (steel scrap/pig iron ratio, superheating level), pouring temperature, and inoculation treatment (type and amount of inoculant, nodule count) ${ }^{[13-22]}$.

The combination of thermal (cooling curve) analysis technique with contraction curve analysis technique, for simultaneous evaluation of the most important events associated with liquid to solid transition and solid state cooling to room temperature, could offer more useful information on the quality of metal castings ${ }^{[23-25]}$.

The aim of the present study is to review original data obtained by the authors from recent separate publications with additional unpublished data, specifically concerning a technique to simultaneously evaluate cooling curves and expansion or contraction of cast metals during solidification using a specialized software. New data was added to deeply correlate the most important events between the cooling and contraction curves, to evaluate the sensitivity to shrinkage formation.

\section{Experimental procedure}

In laboratory research programs, different variants of equipment able to simultaneously (real time) evaluate the solidification cooling and contraction curves were tested, in order to identify the most representative parameters useful to foresee the structure characteristics and possible contraction defects occurrence. Grey (lamellar graphite), ductile (nodular graphite) and white (carbidic, no graphite) cast irons were considered ${ }^{[26-33]}$. Figures 1 and 2 illustrate two such equipment setups, with obtained results shown in the present work.

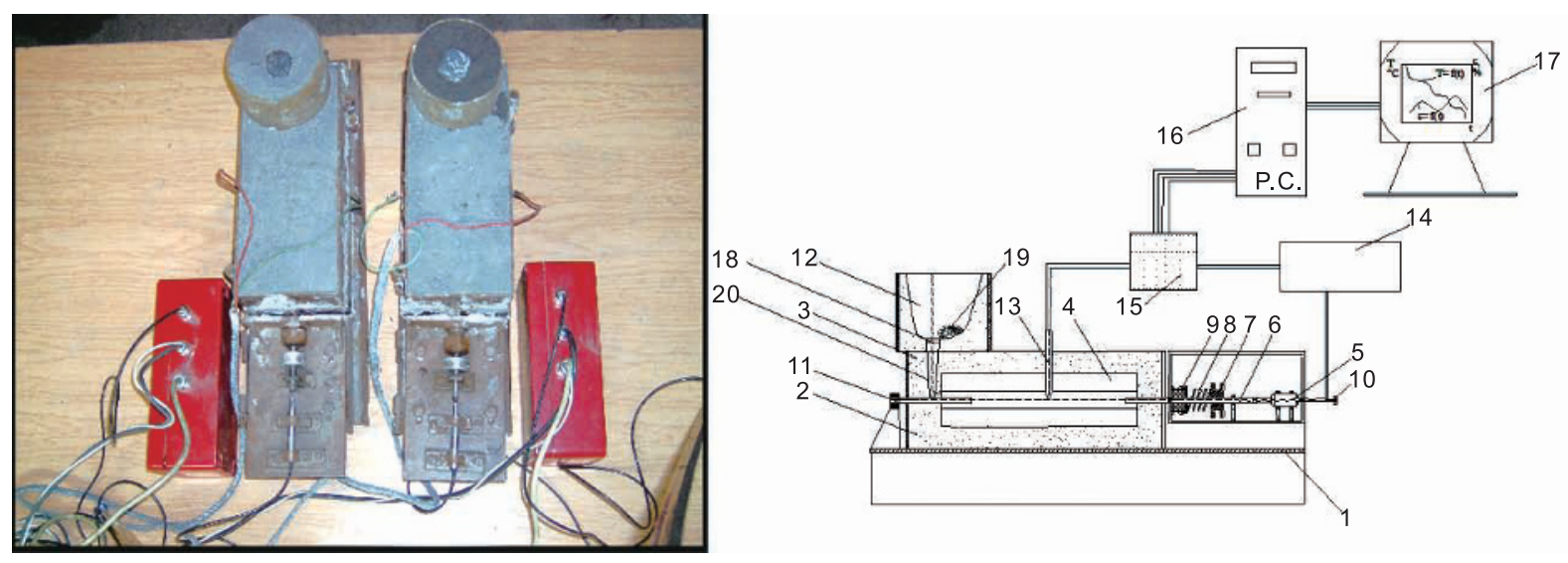

1. Stand; 2. Lower mold; 3. Upper mold; 4. Sample (bar); 5. Displacement transducer; 6. Mobile rod; 7. Thermal radiant; 8. Pretensioning spring;

9. Spring tensioning screw; 10. Fine regulation screw; 11. Rigid rod; 12. Pouring basin; 13. K- type thermocouple; 14. L.V.D.T. amplifier;

15. Connector box; 16. Computer (AT- MIO 10 interface); 17. Display monitor; 18. Fusible steel plate; 19. Inoculant; 20. Sprue

Fig. 1: Arrangement of twin mould cooling and contraction/expansion curves analyzer (CCCA) and representative components (Program I) ${ }^{[26-30]}$ 
(a)
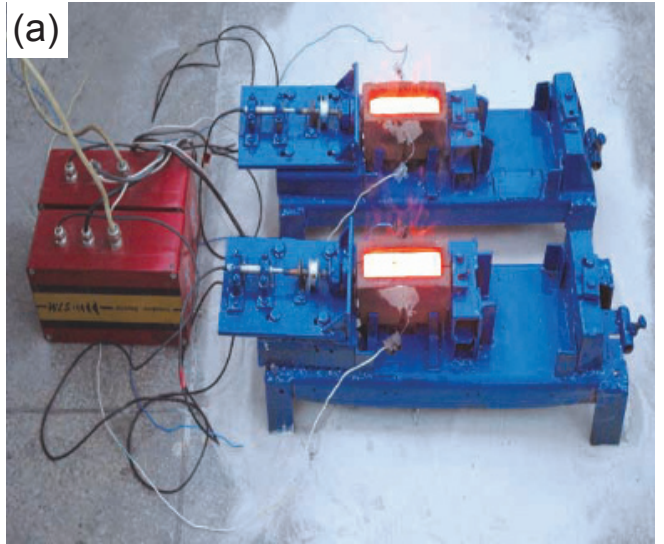

(b)

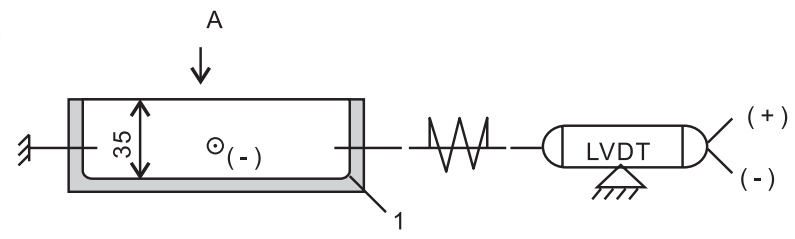

A-view

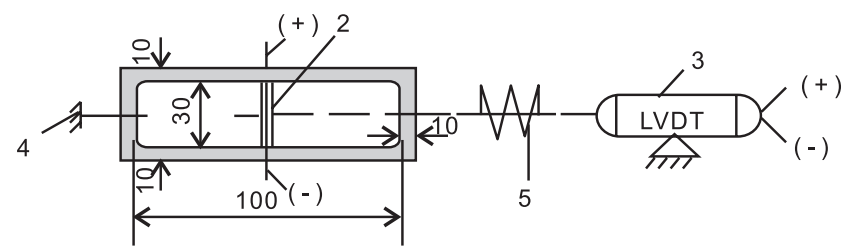

Fig. 2: View of shell ceramic cup - cooling and contraction/expansion curve analyzer (CCCA) (a) and schematic layout (b): 1- Interchangeable shell mould (long-cup) ; 2- K-type thermocouple; 3- Inductive linear displacement transducer (Programs II - V)

The equipment setup in Fig. $1^{[26-30]}$ shows the possibility to simultaneously use two moulds in different positions to repeat experiments two times in the same conditions, to compare two different moulds (as materials or achievement conditions), two metallurgical treatments (Mg-treatment or inoculation alloys, as type or addition rate), and different cast iron chemical compositions. In the present study, green sand mould (GSM) and resin sand mould (RSM) were used, at different positions [GSM: 60-70 Dietert hardness (MDH) on the mould separation plane and $125 \mathrm{~N} \cdot \mathrm{cm}^{-2}$ of compressive strength on standard cylindrical samples; RSM: about $89 \mathrm{MDH}$ and 1,400 $\mathrm{N} \cdot \mathrm{cm}^{-2}$ tensile strength on standard samples]. At higher rigidity, resin sand moulds are characterized by $30 \%$ lower thermal diffusivity (MTD), as shown in Fig. $3^{[30]}$.

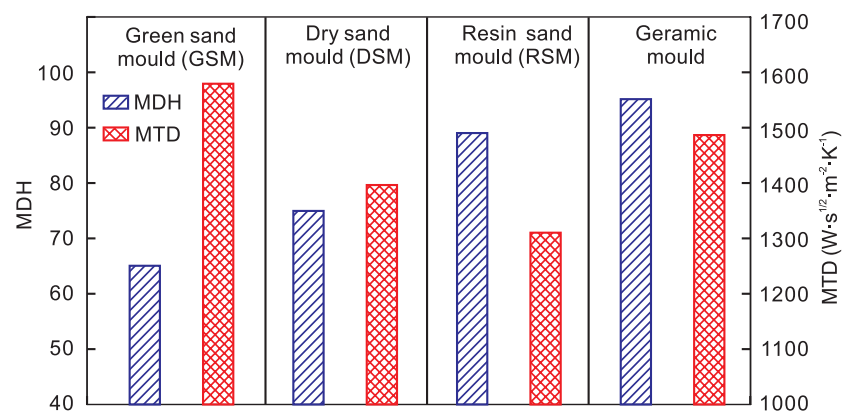

Fig. 3: Typical hardness (MDH) and thermal diffusivity (MTD) of commonly used moulding materials

According to previous research results ${ }^{[26-30]}$, the equipment presented in Fig. 1 includes a linear displacement transducer (LVDT, type D5/100AG) and a transducer for temperature (K-type thermocouple). The equipment stand includes two moulds (sample with a $200 \mathrm{~mm}$ length and $30 \mathrm{~mm}$ square cross section bar, at $7.2 \mathrm{~mm}$ cooling modulus). A high speed type AT-MIO10 interface for simultaneous temperature and linear displacement data recording was applied. A pouring basin was used to inoculate the Mg-treated iron, while the tapping of inoculated iron was controlled by a fusible steel plate. The recorded data were processed using a specialized software created in a LabView program, which is able to simultaneously display both cooling and contraction curves and their parameter readings. The program is suitable for a frequency of 5,000 readings per second and the displaying rate of 10 samples per second, each sample containing an average of 500 readings. The assembly for linear displacement measurement was checked, and an opto-mechanic transducer having a precision of $0.001 \mathrm{~mm}$ was used. The thermal analysis system was calibrated by a commercial (Chekmate III/QuikCup) instrument, which claims a resolution of $0.1^{\circ} \mathrm{C}$ according to IEC584/IPTS68, for K-type thermocouples. The calibration instrument accuracy is $\left( \pm 0.05 \%+1{ }^{\circ} \mathrm{C}\right)$. The accuracy of the thermal analysis system was evaluated taking into account the full measurements chain that was cup (typical error: $0-2{ }^{\circ} \mathrm{C}$ ), compensation wire (error $\pm 1{ }^{\circ} \mathrm{C}$ ), contact block (error $\pm 1{ }^{\circ} \mathrm{C}$ ) and hardware (error $\pm 1{ }^{\circ} \mathrm{C}$ ). As a result, the calculated error as total measuring chain was $2.65^{\circ} \mathrm{C}$, without calibration. It was reduced to less than $1{ }^{\circ} \mathrm{C}$ after calibration.

The second equipment setup (Fig. 2), with more details presented in previous literature ${ }^{[28,30-33]}$, was developed to be used in a foundry melting shop, similarly with the conventional thermal analysis device, but with the possibility to add new information on conventional thermal analysis parameters, referring to the casting sensitivity to contraction defects formation. The equipment includes a special rigid ceramic cup (Croning process, Dieter hardness 95 and thermal diffusivity $89 \mathrm{~W} \cdot \mathrm{s}^{1 / 2} \cdot \mathrm{m}^{-2} \cdot \mathrm{K}^{-1}$, both of these parameters are higher comparing to resin sand mould), and a resultant cast iron sample (750 g) with a cooling modulus $(\mathrm{CM})$ of $7.0 \mathrm{~mm}$ (close to the first test equipment in Fig. 1 and standard thermal analysis devices). It features a high speed type PCI-6284 interface to record simultaneous temperature and linear displacement data.

Table 1 summarizes the research programs included in the present paper, with information of the considered influencing factors, such as mould rigidity, inoculating elements and inoculant type, graphite morphology, with information on the nodularization and inoculation procedures (applied technique, treatment alloy type and addition rate), mould used, and obtained sample parameters. 
Table 1: Experimental parameters*

\begin{tabular}{|c|c|c|c|c|c|c|c|c|}
\hline No. & $\begin{array}{l}\text { Influencing } \\
\text { factors }\end{array}$ & Iron & CE (\%) & Nodularization & Inoculation & Mould & Sample & Ref. \\
\hline I & $\begin{array}{l}\text { Mould rigidity } \\
\text { Inoculant type }\end{array}$ & DI & $4.5-4.6$ & $\begin{array}{l}2.5 w t . \% \\
\text { FeSiCaMgRE } \\
\text { Tundish cover }\end{array}$ & $\begin{array}{l}0.2 \mathrm{wt} . \%-\mathrm{CCCA} \\
\text { Basin } \\
\text { Zr,Ca-FeSi } \\
\mathrm{Ca}, \mathrm{Ba}-\mathrm{FeSi} \\
\mathrm{Ce}, \mathrm{Ca}, \mathrm{S}, \mathrm{O}-\mathrm{FeSi}\end{array}$ & $\begin{array}{l}\text { Green sand mould } \\
(60-70 \mathrm{DH}) \\
\text { Resin sand mould } \\
(89 \mathrm{DH})\end{array}$ & $\begin{array}{l}30 \times 30 \times 200(\mathrm{~mm}) \\
\text { CM: } 7.2 \mathrm{~mm}\end{array}$ & $\begin{array}{l}{[26]} \\
{[27]} \\
{[28]} \\
{[29]} \\
{[30]}\end{array}$ \\
\hline II & $\begin{array}{l}\text { RE vs La } \\
\text { inoculation }\end{array}$ & DI & 4.3 & $\begin{array}{l}2.5 \mathrm{wt} . \% \\
\text { FeSiCaMg } \\
\text { Tundish cover }\end{array}$ & $\begin{array}{l}0.15 \text { wt. \% in-mould } \\
\text { (CCCA-cup) } \\
\text { RE,Ca-FeSi } \\
\text { La,Ca-FeSi }\end{array}$ & \multirow{6}{*}{$\begin{array}{c}\text { Shell mould } \\
\text { Ceramic cup } \\
\text { [95 DH] }\end{array}$} & \multirow{6}{*}{$\begin{array}{l}30 \times 35 \times 100(\mathrm{~mm}) \\
\text { CM: } 7.0 \mathrm{~mm}\end{array}$} & [28] \\
\hline III & $\begin{array}{l}\text { Graphite } \\
\text { morphology }\end{array}$ & DI & 4.2 & $\begin{array}{l}2.5 w t . \% \\
\text { FeSiCaMg } \\
\text { Tundish cover }\end{array}$ & $\begin{array}{l}0.10 \text { wt. \% in-mould } \\
\text { (CCCA-cup) } \\
\text { Ca,Ba-FeSi } \\
0.15 \text { wt.\% in-mould } \\
\text { (CCCA-cup) } \\
\text { RE,Ca-FeSi }\end{array}$ & & & [30] \\
\hline IV & $\begin{array}{l}\text { Graphite } \\
\text { morphology }\end{array}$ & GI & $4.1-4.2$ & $\begin{array}{l}\text { 2.5wt.\% } \\
\text { FeSiCaMgRE } \\
\text { Tundish cover }\end{array}$ & $\begin{array}{l}0.50 w t . \% \\
\text { Ca,Ce,S,O-FeSi } \\
\text { Pouring ladle }\end{array}$ & & & [31] \\
\hline & $\begin{array}{l}\text { Graphite } \\
\text { vs carbide }\end{array}$ & GI & $3.6-3.8$ & - & $\begin{array}{l}0.15 w t . \% \mathrm{Sr}-\mathrm{FeSi} \\
\text { Pouring ladle }\end{array}$ & & & \\
\hline \multirow[t]{2}{*}{ V } & NG vs LG & DI & $4.0-4.1$ & $\begin{array}{l}\text { 2.5wt.\% } \\
\text { FeSiCaMgRE } \\
\text { Tundish cover }\end{array}$ & $\begin{array}{l}0.50 w t . \% \\
\text { Ca,Ce,S,O-FeSi } \\
\text { Pouring ladle }\end{array}$ & & & $\begin{array}{l}{[32]} \\
{[33]}\end{array}$ \\
\hline & & WI & 3.6 & & $\begin{array}{l}\text { Te-addition } \\
\text { (CCCA-cup) }\end{array}$ & & & \\
\hline
\end{tabular}

Note: GI-grey iron; DI-ductile iron; WI-white iron; CE-carbon equivalent; CCCA-Cooling Contraction Curves Analyzer; NG-nodular graphite; LG-lamellar graphite; RE-rare earth elements; DH-Dietert hardness; CM-cooling modulus; Program I: Equipment in Fig. 1; Programs II, III, IV, V: Equipment in Fig. 2

\section{Results and discussion}

Figure 4 illustrates a general view of the typical cooling curve $[T=f(t)]$ and it's first derivative $[d T / d t=f(t)]$, and the contraction curve $[\varepsilon=f(t)]$ and its first derivative $[d \varepsilon / d t=f(t)]$, respectively.

Some important temperatures, which are involved in the structure formation and casting size evolution during solidification were identified using the cooling curve together with its first derivative curve:

$T_{\mathrm{SEF}}$ - the start temperature of the eutectic freezing (nucleation), which is marked by the lowest position of the first derivative of the cooling curve at the beginning of solidification;

$T_{\mathrm{EU}}-$ the lowest and $T_{\mathrm{ER}}-$ the highest eutectic temperatures, corresponding to zero values on the first derivative; their difference represents the eutectic recalescence, $\Delta T_{r}=T_{\mathrm{ER}}-T_{\mathrm{EU}}$;

$T_{\text {ES }}$ - the temperature at the end of solidification, corresponding to the lowest position of the first derivative at the end of solidification.

By comparing the temperatures $T_{\mathrm{EU}}, T_{\mathrm{ER}}$ and $T_{\mathrm{ES}}$ to the stable (graphitic) $\left(T_{\mathrm{st}}\right)$ and metastable (carbidic) $\left(T_{\mathrm{mst}}\right)$ eutectic temperatures, representative solidification undercooling degrees are obtained:

$$
\begin{aligned}
& \Delta T_{\mathrm{m}}=T_{\mathrm{st}}-T_{\mathrm{EU}},{ }^{\circ} \mathrm{C} \\
& \Delta T_{1}=T_{\mathrm{EU}}-T_{\mathrm{mst}},{ }^{\circ} \mathrm{C} \\
& \Delta T_{2}=T_{\mathrm{ER}}-T_{\mathrm{mst}},{ }^{\circ} \mathrm{C} \\
& \Delta T_{3}=T_{\mathrm{ES}}-T_{\mathrm{mst}},{ }^{\circ} \mathrm{C}
\end{aligned}
$$

Undercooling degrees obtained by referring to the metastable eutectic temperature $\left(T_{\mathrm{mst}}\right)$ offer important practical information, such as:

$\Delta T_{1}<0$ and $\Delta T_{2}<0$ : no graphite possibility and white (carbidic) cast iron formation;

$\Delta T_{1}<0$ and $\Delta T_{2}>0$ : carbide at the beginning and graphite at the end of the eutectic reaction, resulting in mottled cast iron;

$\Delta T_{1}>0$ and $\Delta T_{2}>0$ : only graphite possibility and graphitic cast iron formation (lower value of $\Delta T_{1}$, higher undercooling solidification and undercooled graphite morphologies occurrence in grey cast iron, respectively);

$\Delta T_{3}$ is usually less than 0 : the greater the negative level, the higher occurrence of inter-eutectic cells defects (carbides, micro-shrinkage, etc).

The couple of the contraction curve $[\varepsilon=f(t)]$ and its first derivative $[d \varepsilon / d t=f(t)]$, recorded simultaneously with cooling 


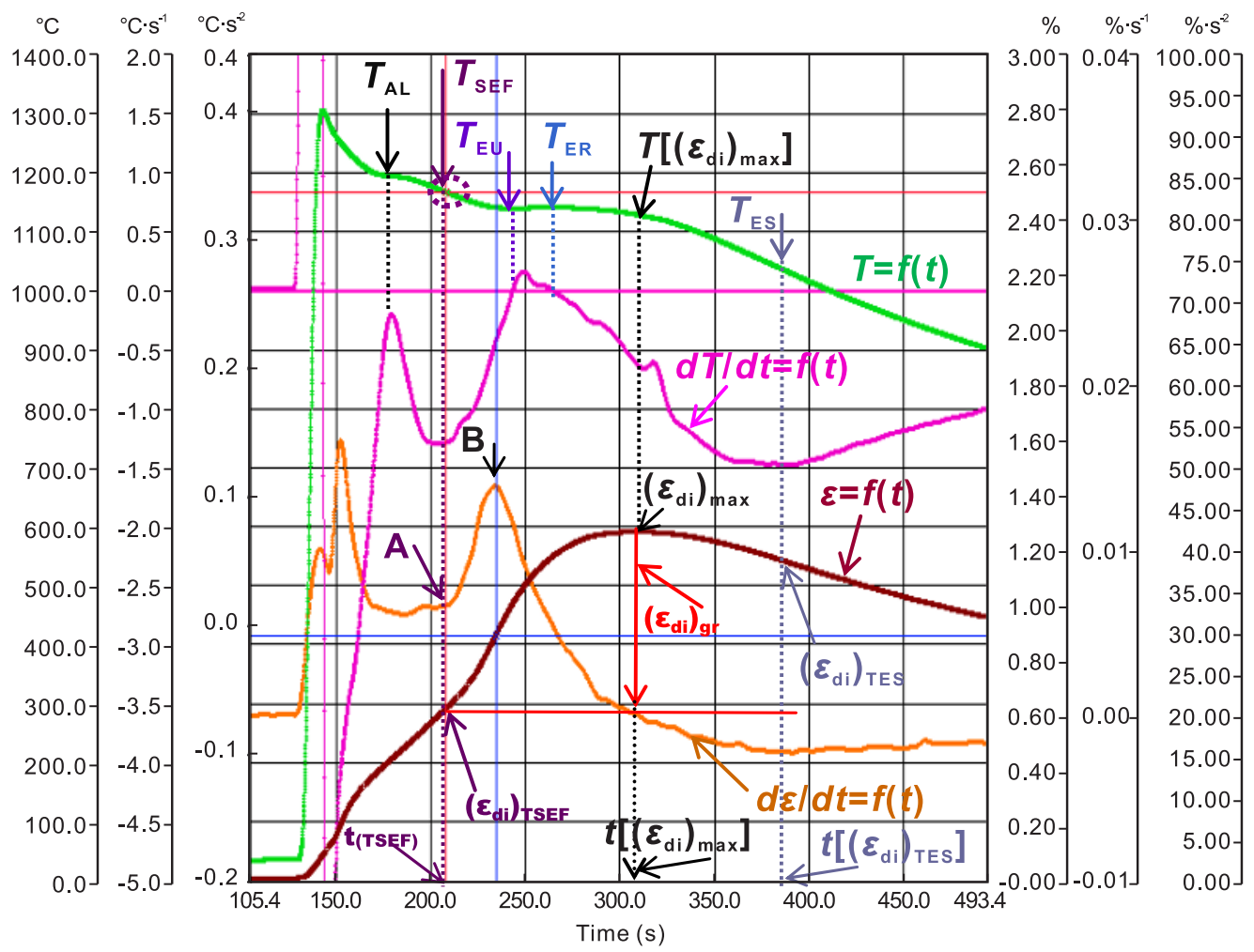

Fig. 4: Typical cooling curve $[T=f(t)]$ and its first derivative $[d T / d t=f(t)]$, and contraction curve $[\varepsilon=f(t)]$ and its first derivative $[d \varepsilon / d t=f(t)]$ for hypoeutectic ductile cast iron solidification $\left[T_{\mathrm{AL}}\right.$ - temperature of austenitic liquidus, ${ }^{\circ} \mathrm{C}$; $T_{\mathrm{SEF}}$ - temperature of the start of eutectic freezing (nucleation), ${ }^{\circ} \mathrm{C} ; T_{\mathrm{EU}}-$ temperature of the maximum eutectic undercooling, ${ }^{\circ} \mathrm{C}$ $T_{\text {ER }}$ - temperature of eutectic recalescence, ${ }^{\circ} \mathrm{C} ; T_{\mathrm{ES}}$ - temperature of the end of solidification, ${ }^{\circ} \mathrm{C} ; \mathrm{A}$ - position on the contraction curve corresponding to $T_{\mathrm{SEF}}$ moment (the beginning of the intensive eutectic graphitization); $\left(\varepsilon_{\mathrm{di}}\right)_{\mathrm{TSEF}}-$ expansion before the start of eutectic freezing, \%; $\left(\varepsilon_{\mathrm{did}}\right)_{\max }-$ maximum expansion, \%; $\left(\varepsilon_{\mathrm{di}}\right)_{\mathrm{TES}}-$ expansion at the end of solidification, \%; $\left(\varepsilon_{\mathrm{di}}\right)_{\mathrm{gr}}=\left(\varepsilon_{\mathrm{di}}\right)_{\max }-\left(\varepsilon_{\mathrm{di}}\right)_{\mathrm{TSEF}}$, graphitic expansion, \%; B - maximum value of the graphitic expansion acceleration]

curve $[T=f(t)]$ and its first derivative $[d T / d t=f(t)]$, shows that the iron casting size starts with an expansion, visible at the pouring moment; it will reach a maximum value $\left[\left(\varepsilon_{\mathrm{di}}\right)_{\max }\right]$, followed by a decreasing evolution which will continue after the end of solidification. Three important events are identified on the expansion/contraction curve:

$\left(\varepsilon_{\mathrm{di}}\right)_{\mathrm{TSEF}}-$ expansion up to the start of eutectic freezing, obtained at $t_{\mathrm{TSEF}}$ time and marked by position $\mathrm{A}$ on the first derivative of the contraction curve, which is corresponding to $T_{\mathrm{SEF}}$ moment (the beginning of the intensive eutectic graphitization);

$\left(\varepsilon_{\mathrm{di}}\right)_{\max }-$ maximum expansion level, obtained at $t\left[\left(\varepsilon_{\mathrm{di}}\right)_{(\max )}\right]$ and corresponding with $T\left[\left(\varepsilon_{\mathrm{di}}\right)_{(\max )}\right]$ temperature, positioned between the highest eutectic temperature $\left(T_{\mathrm{ER}}\right)$ and the temperature of the end of solidification $\left(T_{\mathrm{ES}}\right)$;

$\left(\varepsilon_{\mathrm{di}}\right)_{\mathrm{TES}}$-expansion at the end of solidification, obtained at time of $t\left[\left(\varepsilon_{\mathrm{di}}\right)_{\mathrm{TES}}\right]$ and temperature of $T_{\mathrm{ES}}$.

The difference between the maximum expansion $\left(\varepsilon_{\mathrm{di}}\right)_{\max }$ and the expansion at the start of the eutectic freezing (nucleation) $\left(\varepsilon_{\mathrm{di}}\right)_{\mathrm{TSEF}}$ is attributed to graphite formation, $\left(\varepsilon_{\mathrm{di}}\right)_{\mathrm{gr}}$. For a more clear definition of $\left(\varepsilon_{\mathrm{di}}\right)_{\mathrm{gr}}$ term, two ceramic shell cup samples for simultaneous cooling/contraction curves analysis were poured, one of them with tellurium addition (to promote nongraphite, carbidic structure, white cast iron-WI) while the other without tellurium ensuring a graphitic structure (grey cast iron-GI). In Fig. 5, the simultaneous cooling/contraction curves and their first derivatives evolution in the solidification range for the two tested cast irons (grey and white cast irons) are presented.

It measures an expansion starting already at the moment of the iron melt pouring for both graphitic (GI) and non-graphitic (WI) cast irons up to the start of the eutectic graphitization which is marked by SEG-GI symbol. After that moment, the two contraction curves have totally different evolutions: the grey cast iron expansion curve is continuously increasing because of the eutectic graphite separation, while for the white cast iron, the contraction curve starts because of the primary matrix contraction (no graphite separation). There are different reasons for the common growth (expansion) of the two curves in the first phase of solidification, such as the ferrostatic pressure, silica sand mould expansion, mould movement, etc.

\subsection{Influence of the mould}

Research Program I (Table 1) evaluates the effects of mould characteristics on the solidification pattern of hyper-eutectic ductile cast iron $(4.5 \%-4.6 \%$ carbon equivalent), melted in a graphite crucible induction furnace $(10 \mathrm{~kg}, 8,000 \mathrm{~Hz})$ and treated by tundish cover technique $\left(1,500-1,520{ }^{\circ} \mathrm{C}\right)$, with 2.5 wt. $\%$ FeSiCaMgRE alloy (45.4\% $\mathrm{Si}, 6.1 \% \mathrm{Mg}, 0.6 \% \mathrm{RE}, 0.86 \% \mathrm{Ca}, 0.69 \% \mathrm{Al}) .0 .2 \mathrm{wt} . \%$ FeSi-based inoculants (0.2-0.7 mm grain size) were added into the pouring basin of the cooling/contraction curves analyser (CCCA) before the $\mathrm{Mg}$-treated iron pouring $\left(1,350-1,380{ }^{\circ} \mathrm{C}\right)$. The final 


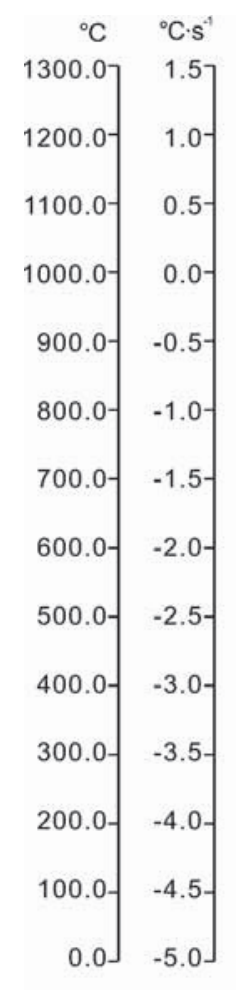

${ }^{\circ} \mathrm{C} \cdot \mathrm{s}^{-2}$

$$
\begin{aligned}
& 0.4 \\
& 0.4
\end{aligned}
$$

$0.4=$

0.3

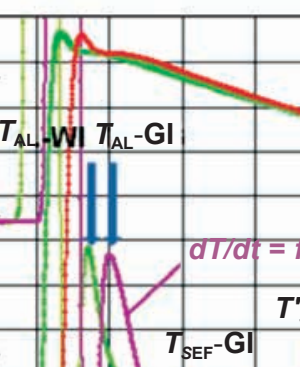

0.2

0.1

0.1
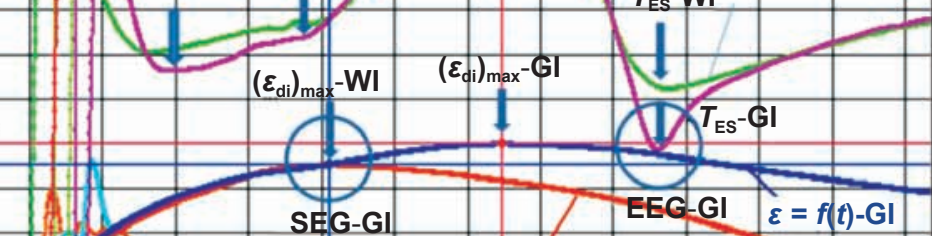

-

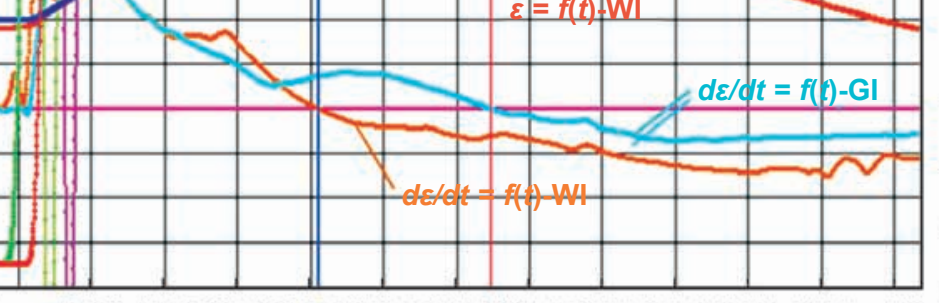

$150.0175 .0200 .0225 .0250 .0275 .0300 .0325 .0350 .0375 .0400 .0 \quad 433.1$

Time (s)

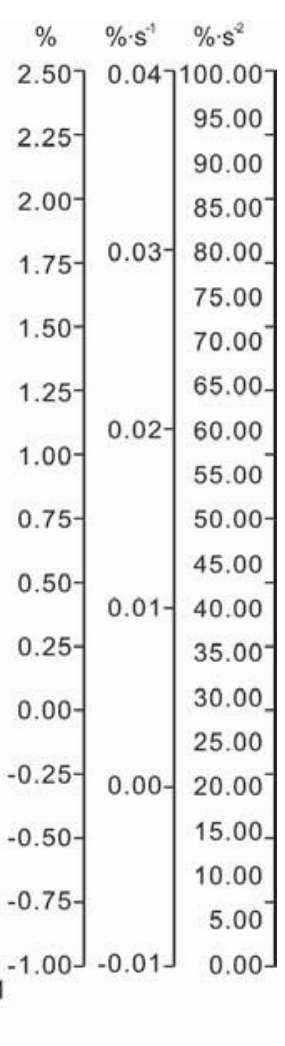

Fig. 5: Simultaneous cooling and expansion/contraction curves and their first derivative evolution in the solidification range, for white (WI) and grey (GI) cast irons (SEG-Gr-start of eutectic graphitization; EEG-Gr-end of eutectic graphitization)

chemical compositions include $3.71 \%-3.76 \% \mathrm{C}, 2.57 \%-2.63 \%$ $\mathrm{Si}, 0.08 \%-0.11 \% \mathrm{Mn}, 0.022 \%-0.023 \% \mathrm{P}, 0.010 \%-0.012 \% \mathrm{~S}$, and $0.065 \%-0.075 \% \mathrm{Mg}_{\text {res }}$.

The present study presents the results obtained with two types of moulds (Table 1, Fig. 3), differentiated by rigidity, expressed by mould Dietert hardness (MDH) and mould thermal diffusivity (MTD): green sand mould, $\mathrm{MDH}=60-$ $70, \mathrm{MTD}=98 \mathrm{Ws}^{1 / 2} \cdot \mathrm{m}^{-2} \cdot \mathrm{K}^{-1}$ and resin sand mould, $\mathrm{MDH}=89$, $\mathrm{MTD}=71 \mathrm{Ws}^{1 / 2} \cdot \mathrm{m}^{-2} \cdot \mathrm{K}^{-1}$.

From the results previously reported ${ }^{[26-30]}$, selected data are presented in Figs. $6^{[28]}$ and $7^{[29,30]}$. There is a clear difference in the maximum initial expansion $\left[\left(\varepsilon_{\mathrm{di}}\right)_{\max }\right]$ during solidification of ductile cast iron in the two moulds, the soft green sand mould (GSM) leads to 3-5 higher values comparing to the rigid resin sand mould (RSM).

The maximum initial expansion $\left[\left(\varepsilon_{\mathrm{di}}\right)_{\max }\right]$ is in a good correlation with the soundness characteristics of the obtained ductile iron castings. The CCCA-samples (Fig. 1) are subjected to the evaluation of concentrated shrinkage volume (Cshv, vol.\%), concentrated $\left(\mathrm{Cshs}, \mathrm{cm}^{2}\right)$ and total $\left(\mathrm{Tshs}, \mathrm{cm}^{2}\right)$ shrinkage surface and apparent density $\left(\rho_{1}, \mathrm{~g} \cdot \mathrm{cm}^{-3}\right)$ of inoculated ductile irons solidified in green sand moulds and resin sand moulds (Program I, Table 1).

The concentrated shrinkage volume is obtained by the water displacement method. A more rigid mould (RSM) leads not only to the lower maximum expansion level but also, consequently, to a lower concentrated shrinkage formation sensitivity.

Surface defects occurrence, expressed by Cshs and Tshs

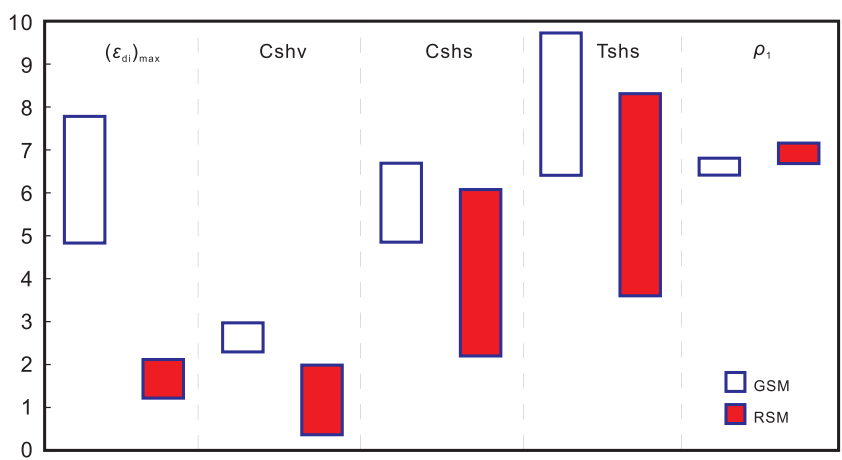

Fig. 6: Maximum initial expansion $\left[\left(\varepsilon_{\mathrm{di}}\right)_{\max } \times 10, \%\right)$, concentrated shrinkage volume (Cshv, vol.\%), concentrated (Cshs, $\mathrm{cm}^{2}$ ] and total (Tshs, $\mathrm{cm}^{2}$ ) shrinkage surface and apparent density $\left(\rho_{1}, \mathrm{~g} \cdot \mathrm{cm}^{-3}\right)$ of inoculated ductile irons solidified in green sand moulds (GSM) and resin sand moulds (RSM) (Program I)

parameters, is also reduced by increasing the mould rigidity. $\mathrm{X}$-Ray investigation is made in the frontal longitudinal plane of the samples to evaluate these parameters. The obtained negative films are scanned and then automatic image analysis is recorded on both concentrated and macro-dispersed shrinkage (as absolute and relative surface). According to Fig. 6, the apparent density of ductile iron castings $\left(\rho_{1}\right)$, obtained in the region where all of the shrinkage types are present, is lower in soft (compressible) green sand mould, which is favourable to higher expansion of casting during solidification. 

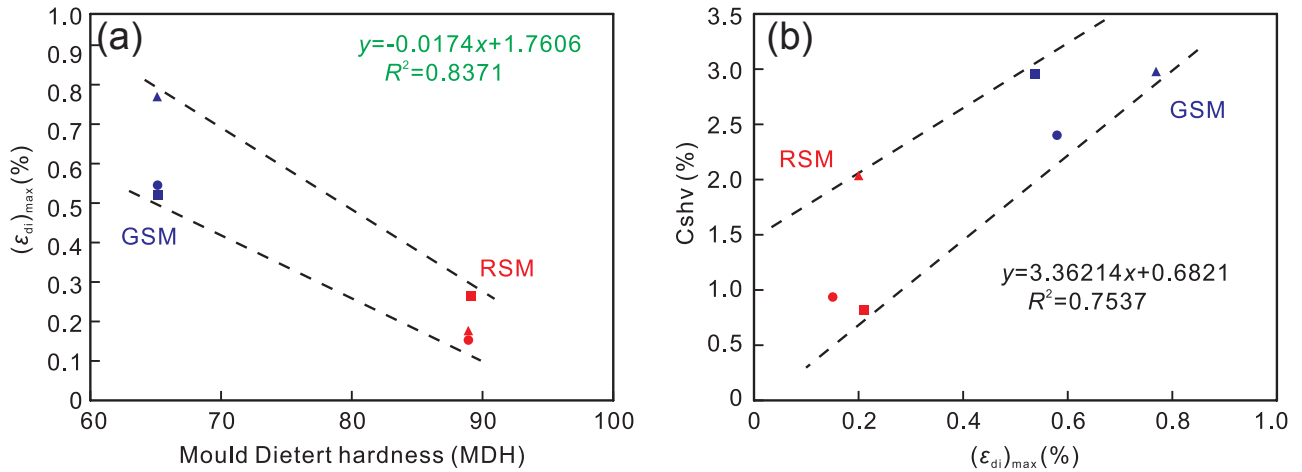

Fig. 7: Influence of mould Dietert hardness on maximum initial expansion $\left(\varepsilon_{\mathrm{di}}\right)_{\max }(\mathrm{a})$ and of $\left(\varepsilon_{\mathrm{di}}\right)_{\max }$ on the concentrated shrinkage volume (Cshv, vol.\%) (b) for Program I

\subsection{Influence of inoculating elements}

Based on the Program I (Table 1), the solidification pattern of ductile iron CCCA-analyser samples was evaluated with different $\mathrm{FeSi}$-based inoculants including the inoculating elements $\mathrm{Ca}-\mathrm{Ba}$ (Inoculant $\mathrm{F}$ ), $\mathrm{Ca}-\mathrm{Zr}$ (Inoculant $\mathrm{Z}$ ) and $\mathrm{Ca}, \mathrm{Ce}-$ $\mathrm{S}$, O (Inoculant $\mathrm{U}$ ) ${ }^{[26-30]}$. Figure 8 confirms the important role of the higher mould rigidity to obtain a lower level of the maximum

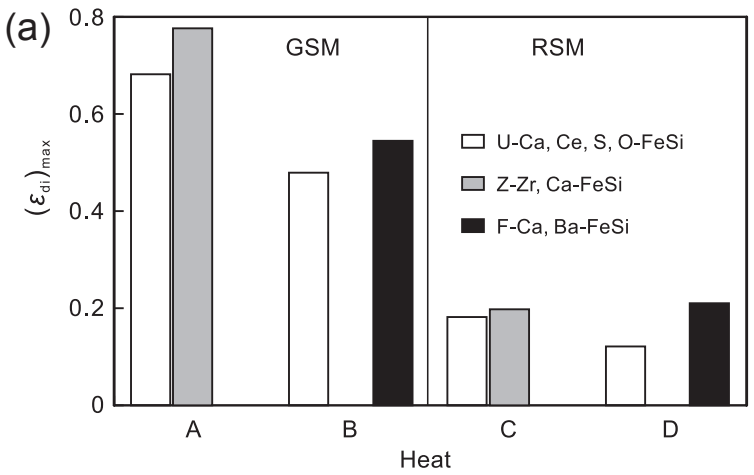

initial expansion parameter (Fig. 8a), and, consequently, a lower tendency to contraction cavity formation (Fig. 8b) ${ }^{[27]}$. In the same Mg-treatment and inoculation applied procedures, and in the same solidification conditions of cooling modulus of casting and mould media characteristics, inoculant type (inoculating elements) could have an important effect on the contraction curve parameters and soundness of ductile iron castings.

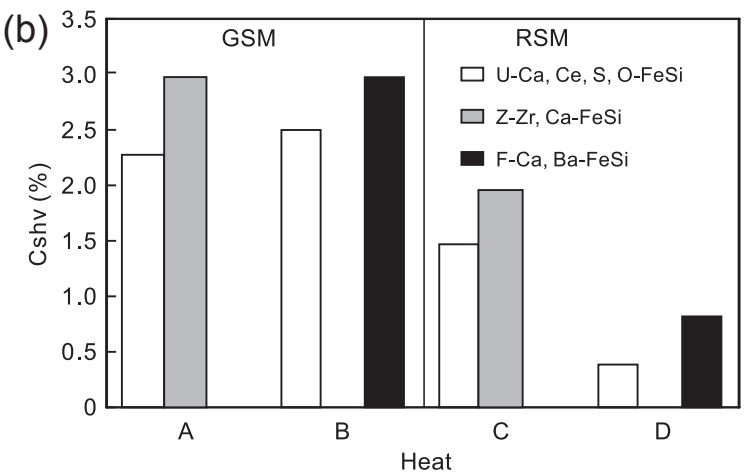

Fig. 8: Influence of mould (GSM, RSM) and inoculant type (U, Z, F) on maximum initial expansion $\left(\varepsilon_{\mathrm{di}}\right)_{\max }(\mathrm{a})$ and concentrated shrinkage volume (Cshv) (b) for Program I

For both types of moulds, the complex inoculant $(\mathrm{Ca}, \mathrm{Ce}$, $\mathrm{S}, \mathrm{O}-\mathrm{FeSi}$ alloy) leads to a lower level of $\left(\varepsilon_{\mathrm{di}}\right)_{\max }$ and Cshv parameters. This means that this inoculated ductile cast iron will solidify at a lower graphitic force acting on the mould wall, resulting in a reduced enlargement of the mould cavity, and formed contraction defects. The previous published papers illustrated some specific effects of this inoculant, such as higher graphite nodularity and nodule count, and at a peculiar size distribution, fewer large nodules sized above $50 \mu \mathrm{m}$ (up to $15 \%$ ) probably formed at the beginning of solidification and therefore also having a higher proportion of small nodules sized less than $30 \mu \mathrm{m}$ (more than $80 \%$ ) at the final stage of solidification. Other investigations also reported such peculiar behaviour of $\mathrm{Ca}, \mathrm{Ce}, \mathrm{S}$, O-FeSi inoculant ${ }^{[11,17,20,34,35]}$.

The influence of inoculating elements is also evaluated in another research program (II, Table 1) using the cooling/ contraction curve analyser presented in Fig. 2, characterized by using a ceramic shell mould having a half-length $(L=100 \mathrm{~mm})$ sample with a similar cooling modulus $(\mathrm{CM}=7.0 \mathrm{~mm})$ [Fig. 2(b)]. The ceramic shell mould has a high rigidity (95 DH), specific for foundry application. In these experiments, ductile cast iron is obtained by $2.5 \mathrm{wt} . \% \mathrm{FeSiCaMg} 5.5$ (no rare earth elements) tundish cover treatment, followed by $0.15 \mathrm{wt} . \%$ FeSi-based alloys inoculation (inside of the CCCA), including rare earth elements, but of different types: mischmetall, RE2.3Ca1.2-FeSi alloy and La1.8Ca1.1-FeSi alloy, respectively ${ }^{[28]}$. Figure 9(a) shows the values of the solidification undercooling of the un-inoculated (U.I) and inoculated ductile irons obtained on the cooling curve and its first derivative. Figure 9(b) shows the representative expansion of casting parameters of the inoculated cast irons measured in three representative moments on the expansion/contraction curve (Fig. 4).

As normally expected, inoculation, as graphitizing treatment applied to the Mg-treated iron melt before solidification, reduces the solidification undercooling, expressed by decreasing $\Delta T_{\mathrm{m}}$ and $\Delta T_{3}$ (less negative) and increasing $\Delta T_{1}$ and $\Delta T_{2}$ parameters, for both compared inoculants. These two inoculants differentiated by the inoculation power, in the same applied conditions. The La-bearing FeSi alloy has a higher graphitizing capacity, as undercooling parameters are in better position comparing to RE-bearing FeSi alloy. 

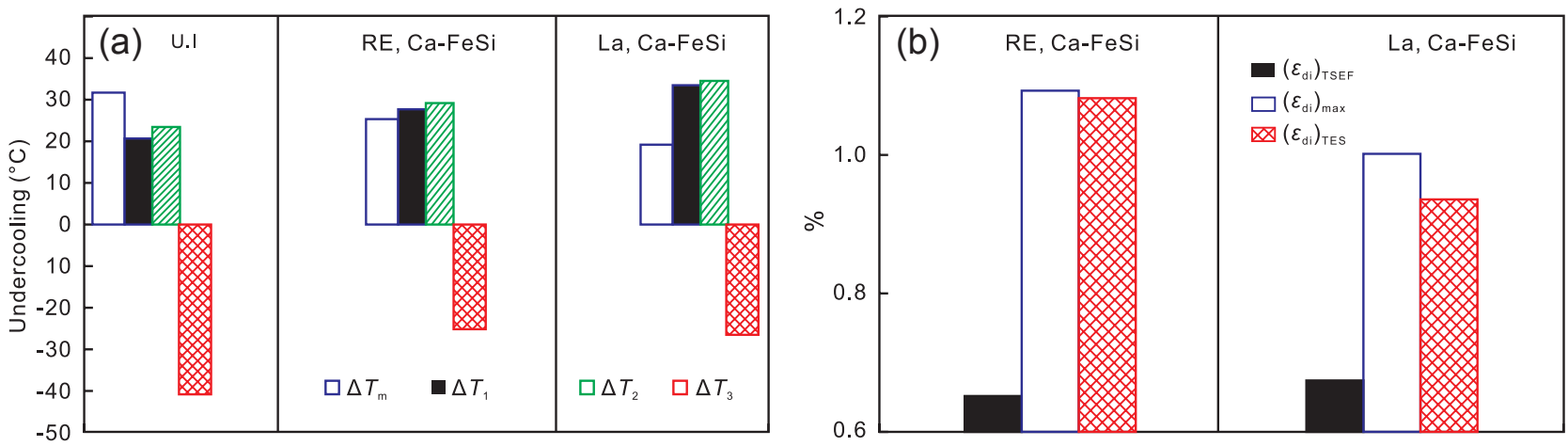

Fig. 9: Representative solidification undercooling levels (a) and parameters on contraction curve and its first derivative (b) of RE, Ca-FeSi and La, Ca-FeSi inoculated ductile cast irons (Program II)

The expansion was measured corresponding to the temperature at the start of eutectic freezing/nucleation, $T_{\mathrm{SEF}}$, the expansion up to the start of eutectic freezing, $\left(\varepsilon_{\mathrm{di}}\right)_{\max }$, the maximum level of expansion, $\left(\varepsilon_{\mathrm{di}}\right)_{\mathrm{TSEF}}$, and the expansion at the end of solidification (marked by $T_{\mathrm{ES}}$ temperature), $\left(\varepsilon_{\mathrm{di}}\right)_{\mathrm{TES}}$, respectively. For the two inoculated ductile cast irons, the obtained results are presented in Fig. 9(b). La-bearing FeSi inoculant leads to a lower level of the maximum expansion of the ductile iron casting, which is found to be favourable to lower shrinkage formation tendency (Figs. 6-8). These results confirm the lower occurrence of contraction defects found in ductile iron castings treated by Labearing MgFeSi alloy ${ }^{[11,17,34-36]}$

\subsection{Ductile iron versus grey iron}

Experiments were carried out to compare the low carbon equivalent (3.5\%, strong hypo-eutectic position), high strength grey iron (lamellar graphite) and eutectic ductile cast iron (4.2\% carbon equivalent) solidification patterns (Program III, Table 1), by using the cooling and contraction curve analyzer (CCCA) presented in Fig. $2^{[30]}$.

Experimental cast irons were obtained by melting in an electric induction furnace and treated according to the conventional procedure for these materials: the grey cast iron was inoculated by $0.10 \mathrm{wt} . \% \mathrm{Ca} 1.5 \mathrm{Ba} 2.8-\mathrm{FeSi}$ alloy; ductile cast iron was obtained by $2.5 \mathrm{wt} . \% \mathrm{FeSiCaMg} 5.5$ treatment by tundish cover technique followed by $0.15 \mathrm{wt} . \%$ RE2.3Ca1.2FeSi inoculation. In both cases, inoculation alloy $(0.2-0.7 \mathrm{~mm}$ grain size) is added into the CCCA-ceramic cup before iron melt pouring. Pearlitic grey cast iron (less than 5\% carbides) contains more than $70 \%$ lamellar graphite Type A, according to ISO 945 standard, in the sample solidified in CCCA-Fig. 2 conditions. The obtained ductile iron, in the same type of samples, is characterized by more than $70 \%$ ferrite, containing no carbides, at more than $70 \%$ graphite nodularity.

Selected experimental data are shown in Fig. 10, which shows the solidification undercooling at the beginning of eutectic reaction $\left(\Delta T_{\mathrm{m}}, \Delta T_{1}\right)$ and at the end of solidification $\left(\Delta T_{3}\right)$. The solidification intervals, starting with the liquidus temperature $\left(T_{\mathrm{L}}\right)$ to the lowest eutectic temperature $T_{\mathrm{EU}}\left[\tau_{\text {(TL-TEU) }}\right]$, the interval from the highest eutectic temperature $T_{\mathrm{ER}}$ to the end of solidification $T_{\text {ES }}\left[\tau_{\text {(TER-TES) }}\right]$, and the entire solidification interval from $T_{\mathrm{L}}$ up to $T_{\text {ES }}\left[\tau_{\text {(TL-TES })}\right]$, are compared between grey and ductile cast irons (Fig. 10b). The values of the maximum expansion $\left(\varepsilon_{\mathrm{di}}\right)_{\max }$ and the expansion attributed to graphite formation $\left(\varepsilon_{\mathrm{di}}\right)_{\mathrm{gr}}=\left(\varepsilon_{\mathrm{di}}\right)_{\max }-$ $\left(\varepsilon_{\mathrm{di}}\right)_{\mathrm{TSEF}}$ are included in Fig. 10(b).

To evaluate the solidification undercooling, the calculated stable eutectic temperature $\left(T_{\mathrm{st}}=154+4 \mathrm{Si}-2 \mathrm{Mn}-30 \mathrm{P},{ }^{\circ} \mathrm{C}\right){ }^{[37]}$ and the measured metastable eutectic temperature $T_{\mathrm{mst}}$ in Te-treated ceramic cups were considered. According to Fig. 10 (a), in the present experimental conditions, the grey cast iron eutectic reaction is characterized by higher undercooling referring to both stable eutectic temperature (higher $\Delta T_{\mathrm{m}}$ ) and metastable eutectic temperature (lower $\Delta T_{1}$ ), respectively, typically for low carbon equivalent level. Grey cast iron is also characterized by higher undercooling at the end of solidification, as $\Delta T_{3}$ parameter is more negative comparing to ductile iron. (a)

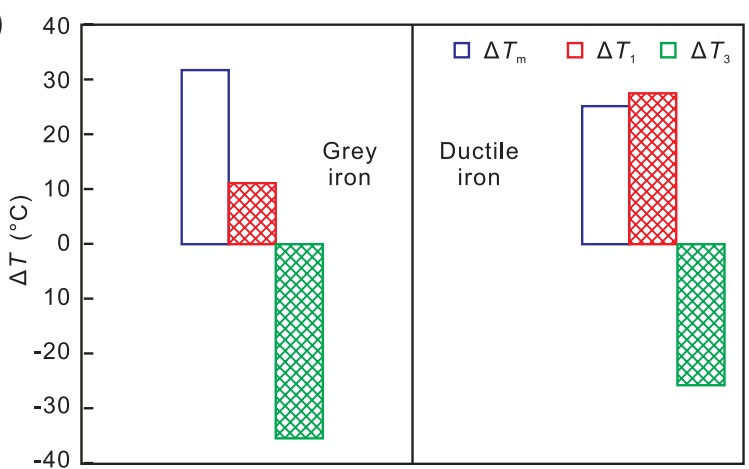

(b)

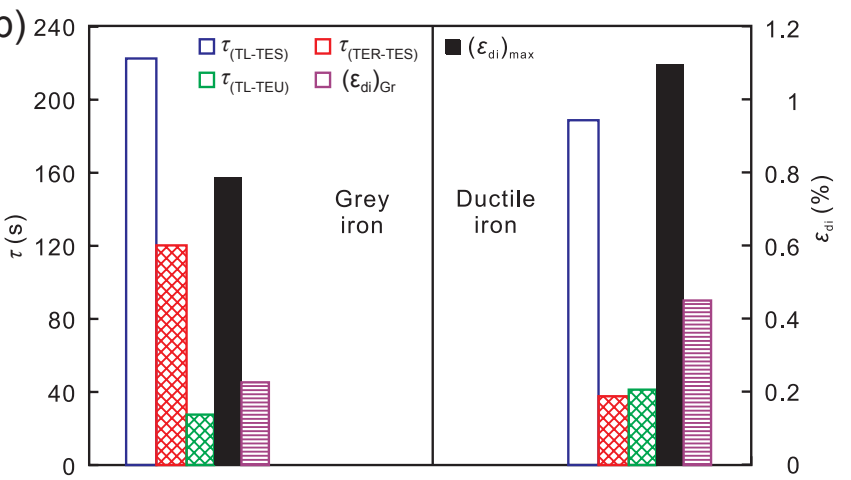

Fig. 10: Representative undercooling levels $(\Delta T)(\mathrm{a})$, and solidification time intervals $(\tau)$ and initial expansion $\left(\varepsilon_{\mathrm{di}}\right)(\mathrm{b})$ (Program III) 
Figure 10 (b) shows that there is a small difference in the total solidification time $\left[\tau_{\text {(TL-TES) }}\right]$ between grey and ductile cast irons. It is only a little bit longer for grey cast iron $(8 \%)$, but with visible difference in specific sub-intervals during solidification: a little bit longer in the first part of the solidification interval $\left[\tau_{\text {(TL-TEU) }}\right]$ and visiblely shorter in the second part interval $\left[\tau_{\text {(TER-TES })}\right]$, for ductile cast iron.

Expansion periods marked on the cooling curve clearly differentiate the two cast irons, including different graphite morphologies. The maximum initial expansion $\left(\varepsilon_{\mathrm{di}}\right)_{\max }$, found to be important in shrinkage and micro-shrinkage formation in the final solidified castings, is $40 \%$ higher for ductile cast iron (Fig. $10 \mathrm{~b})$. It is assumed that the graphite formation, after the start of eutectic freezing (nucleation), will have an important contribution in the total casting expansion; this contribution is calculated as the difference $\left(\varepsilon_{\mathrm{di}}\right)_{\mathrm{gr}}$. This parameter increases two times, to $0.23 \%$ for grey cast iron, and to $0.45 \%$ for ductile cast iron.

According to the present experimental conditions, it is found that high strength grey iron castings are characterized by greater undercooling at the beginning and the end of solidification with less graphitic expansion. Ductile iron displays more graphitic initial expansion, which is inclined towards shrinkage formation in soft moulds.

In an other experimental program (Program IV, Table 1), the grey and ductile irons were compared, at an appropriate carbon equivalent level (3.7\%-3.8\% for grey iron and $4.1 \%$ $4.2 \%$ for ductile iron), which also means appropriate graphite amount possibility formation, respectively ${ }^{[31]}$. The experiments were repeated with 5 heats tested for both grey and ductile cast irons ( 2 samples for each heat). The conventional metallurgical treatments were performed: $0.15 \mathrm{wt} . \% \mathrm{Sr}-\mathrm{FeSi}$ ladle inoculation for grey iron and $2.0 \mathrm{wt} . \% \mathrm{FeSiCaMg} 10 \mathrm{RE} 1$ tundish cover nodularization followed by $0.5 \mathrm{wt} . \% \mathrm{Ca}, \mathrm{Ce}, \mathrm{S}, \mathrm{O}-\mathrm{FeSi}$ ladle inoculation. Solidification process is analyzed by using the equipment presented in Fig. 2, including a high rigidity ceramic cup $[30 \times 35 \times 100(\mathrm{~mm})$ cast iron sample].

"Three cups system" was used to measure the metastable $\left(T_{\mathrm{mst}}\right)$ and stable $\left(T_{\mathrm{st}}\right)$ eutectic temperatures for grey cast irons: one ceramic cup (Quick-cup ${ }^{\mathrm{TM}}$ system) for the analyzed cast iron; the second cup with Te-addition for carbidic (white) cast iron solidification and $T_{\mathrm{mst}}$ measurement; the third cup with over-inoculation for graphitic cast iron solidification and $T_{\text {st }}$ measurement. For ductile cast irons, $T_{\mathrm{st}}$ and $T_{\mathrm{mst}}$ are calculated depending on the final chemical composition, using complex equations established by Ref. [7].

Figure 11 summarizes the results obtained in this experimental program, including the solidification undercooling representative parameters (Fig. 11a), and their relationships with graphitic expansion $\left(\varepsilon_{\mathrm{di}}\right)_{\text {gr }}$ of grey (GI) and ductile (DI) cast irons (Fig. 11b-d). It is confirmed again that greater graphitic initial expansion $\left[\left(\varepsilon_{\mathrm{di}}\right)_{\mathrm{gr}}\right]$, which favours the shrinkage formation, characterizes the nodular graphite iron castings $(0.45 \%-0.7 \%)$ comparing to the lamellar graphite iron castings $(0.08 \%-0.15 \%)$.

For both graphite morphologies, there is a good relationship between considered parameters on the cooling curves and the corresponding events on the contraction/expansion curves, such as the solidification undercooling degrees, comparing to metastable eutectic temperature, and graphitic expansion $\left[\left(\varepsilon_{\mathrm{di}}\right)_{\mathrm{gr}}\right]$ : the higher the $\Delta T_{1}, \Delta T_{2}$ and $\Delta T_{3}$ (less negative), the greater the $\left(\varepsilon_{\mathrm{di}}\right)_{\mathrm{gr}}$, but with stronger relationships for grey cast iron.

Other parameters characterize the capacity of cast iron to form graphite during eutectic reaction, such as the eutectic recalescence $\Delta T_{\mathrm{r}}$ and the graphitic factor GRF1, with visible influence on the expansion due to graphitization (Fig. 11e, f). The eutectic recalescence, $\Delta T_{\mathrm{r}}=T_{\mathrm{ER}}-T_{\mathrm{EU}}$, is resulted from the increasing temperature after the lowest eutectic temperature $\left(T_{\mathrm{EU}}\right)$ moment, as a result of solid eutectic formation, including graphite. According to Fig. 11(e), the higher recalescence leads to higher graphitic expansion, which is more intensive for nodular graphite formation in ductile cast iron.

Graphite, with volume increasing, is formed during the entire eutectic reaction and up to the end of solidification, acting as an important force on the mould walls. In these experiments, graphitic factor [GRF1] is used; it is obtained by measurement of the time necessary to decrease the temperature by $15^{\circ} \mathrm{C}$ after the maximum (recalescence) temperature $T_{\mathrm{ER}}$ moment ${ }^{[1]}$. Generally, the higher the GRF1 factor, the greater the amount of graphite formed in the last part of solidification. Figure 11(f) shows the values of this parameter for experimental grey and ductile cast iron heats, in relationship with the calculated expansion as a result of graphite formation $\left(\varepsilon_{\mathrm{di}}\right)_{\mathrm{gr}}$. Higher average level for GRF1 in ductile iron solidification (48.5 versus 37.6 as average) illustrates the higher capacity to form graphite during the eutectic reaction comparing to grey cast iron.

\subsection{Graphitic cast iron versus carbidic cast iron}

The expansion/contraction curves have different evolutions for grey and ductile cast irons during the same representative intervals, such as up to the start of the eutectic freezing, during eutectic reaction, and up to the end of solidification, respectively. In order to obtain more information on the role of cast iron graphitization, the influence of graphite morphology and the importance of graphite formation in the first or the last part of solidification, a complex research program was recorded ${ }^{[32,33]}$. Cooling and contraction curve analyser (CCCA) presented in Fig. 2 was used.

The experiments compared three hypoeutectic (carbon equivalent $\mathrm{CE}<4.3 \%)$ cast irons: grey $(3.56 \%-3.77 \% \mathrm{CE})$, ductile $(3.98 \%-4.11 \% \mathrm{CE})$ and white $(\mathrm{CE}=3.62 \%-3.64 \%)$ cast irons. The irons were melted in a $10 \mathrm{~kg}$ crucible inside an induction furnace, and the grey cast iron is obtained by $0.15 \mathrm{wt} . \%$ Sr-FeSi ladle inoculation, white cast iron by strong antigraphitizing Te-addition in the CCCA-ceramic cup in the grey iron melt, and ductile iron by typical double treatment: 2.0wt.\% FeSiCaMgRE nodularization by tundish cover technique and ladle inoculation with $0.5 \mathrm{wt} . \% \mathrm{Ca}, \mathrm{Ce}, \mathrm{S}, \mathrm{O}-\mathrm{FeSi}$ alloy. The experiments were repeated, (2 samples for each heat) with 8 heats tested for grey irons, 5 heats for ductile irons and 2 heats for white irons. Each heat was controlled to ensure similar thermal and chemistry histories. For each type of cast iron, experimental heats were obtained from the same metallic charge. 

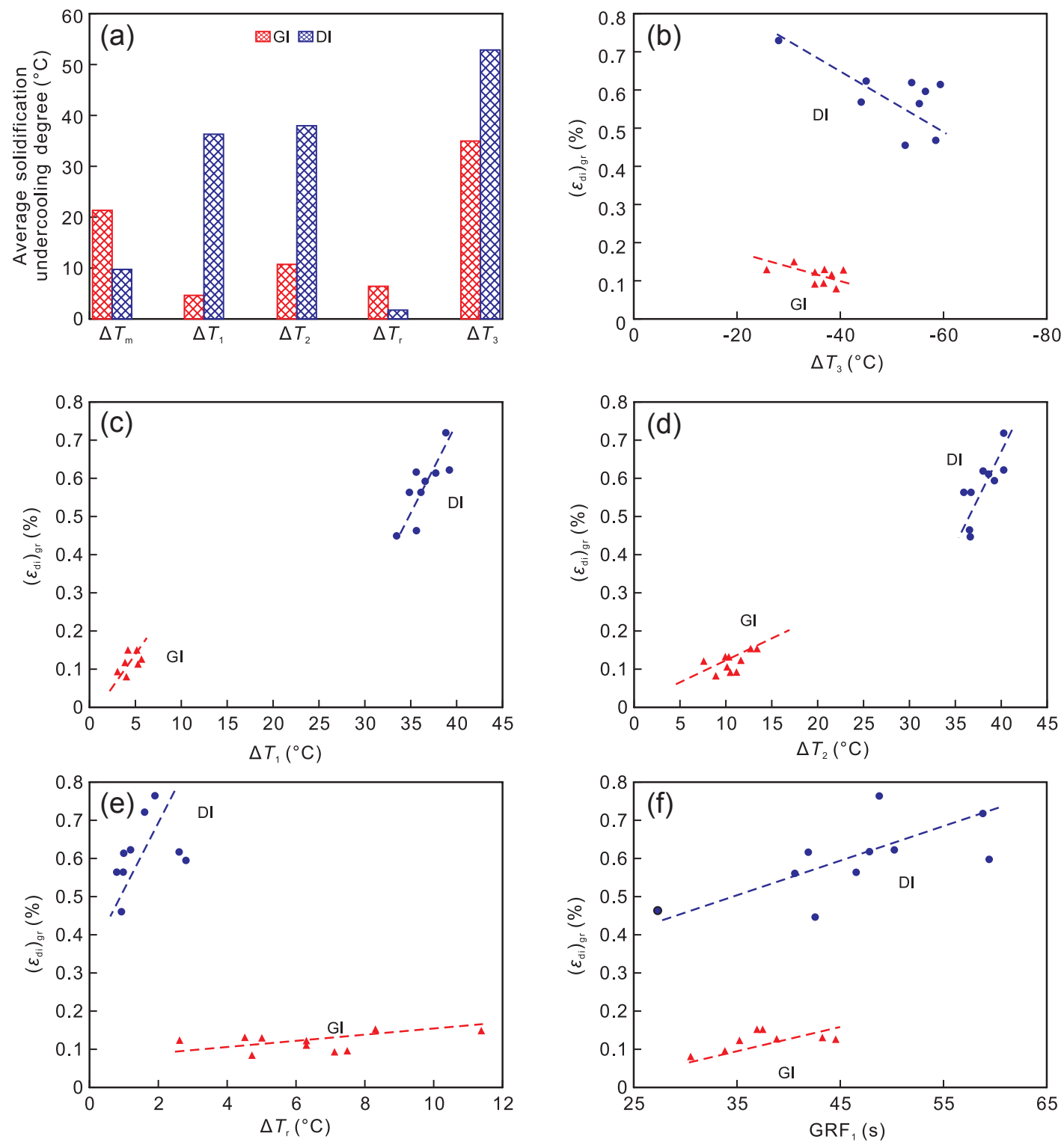

Fig. 11: Representative solidification undercooling parameters (a) and the relationship between graphitic expansion $\left(\varepsilon_{\mathrm{di}}\right)_{\mathrm{gr}}$ and undercooling of the end of solidification $\Delta T_{3}(\mathrm{~b})$, the lowest $\Delta T_{1}(\mathrm{c})$ and the highest $\Delta T_{2}$ (d) eutectic temperatures, eutectic recalescence $\Delta T_{\mathrm{r}}$ (e) and graphitic factor GRF1 (f) of GI and DI (Program IV)

Figure 12 illustrates the typical expansion/contraction curves obtained in this experimental program for the three tested cast irons ${ }^{[32]}$. These curves show some peculiar behaviours, depending on whether the separation of carbon is as carbide or graphite (WI versus GI and DI), and graphite morphology (GI versus DI), respectively. Selected results are included in Figs. $13^{[32]}$ and $14^{[33]}$.

Figure 13 shows the values of measured expansion at the moment of the eutectic freezing $\left(\varepsilon_{\mathrm{di}}\right)_{\mathrm{TSEF}}$ and at the maximum level $\left(\varepsilon_{\mathrm{di}}\right)_{\max }$ for all of experimental heats for grey (GI), ductile (DI) and white (WI) test cast irons. The calculated difference between the maximum value and the value obtained at the start of eutectic freezing is considered to be the expansion challenged by graphite formation during eutectic reaction $\left(\varepsilon_{\mathrm{di}}\right)_{\mathrm{gr}}$

The average level $\left(\varepsilon_{\mathrm{di}}\right)_{\mathrm{TSEF}}(0.44 \%$, Fig. 14a) does not differ for grey (GI), ductile (DI) and white (WI)

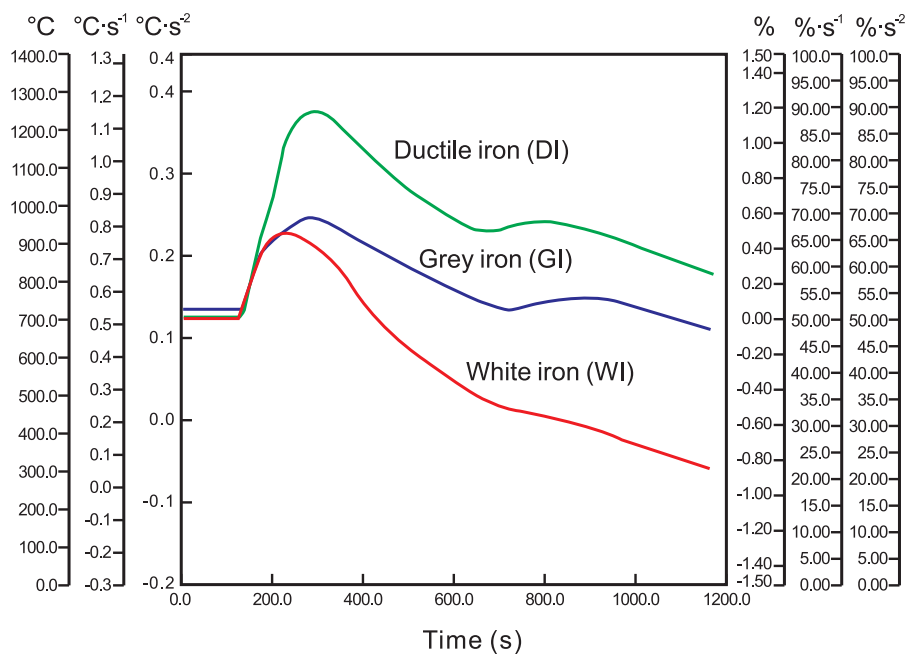

Fig. 12: Typical expansion/contraction curves for white, gray and ductile cast irons (Program V) 


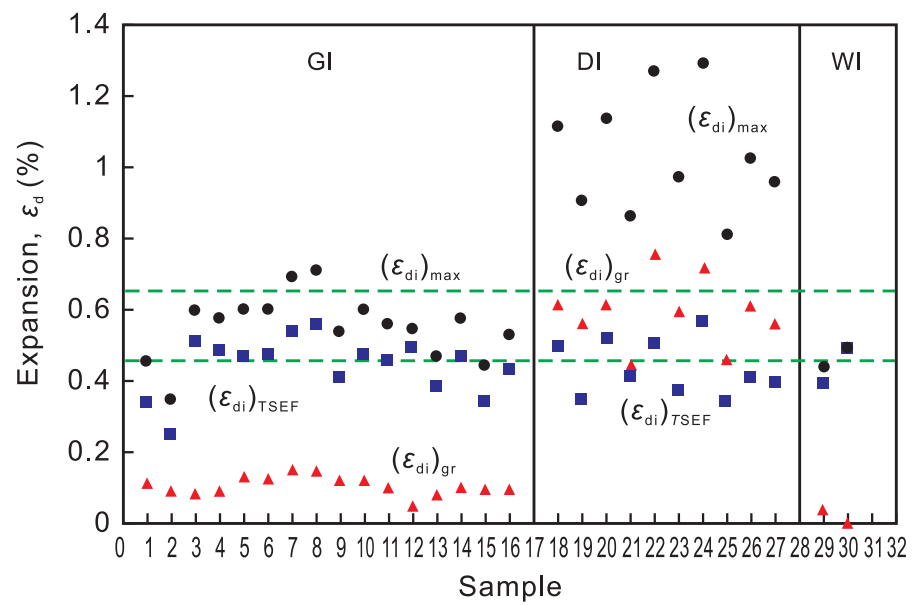

Fig. 13: Initial expansion at the start of eutectic freezing $\left[\left(\varepsilon_{\mathrm{di}}\right)\right.$ TSEF $]$, the maximum initial expansion $\left[\left(\varepsilon_{\mathrm{di}}\right)_{\max }\right]$ and the expansion promoted by eutectic graphite formation $\left[\left(\varepsilon_{\mathrm{di}}\right)_{\mathrm{gr}}\right]$ for grey $[\mathrm{Gl}]$, ductile [DI] and white $(\mathrm{WI})$ test cast irons (Program V)

cast irons solidification, which could have different reasons: the ferrostatic pressure, silica sand mould expansion, mould movement etc. The maximum expansion level $\left(\varepsilon_{\mathrm{di}}\right)_{\max }$, reached at $t\left[\left(\varepsilon_{\mathrm{di}}\right)_{\max }\right]$ time, shortly after the maximum temperature (recalescence) of the eutectic reaction, and before the temperature reached at the end of solidification, clearly differentiated the three tested cast irons. Nodular graphite cast iron (DI) is characterized by the highest level of this parameter (1.032\% as average), two times higher than the other graphitic cast iron (GI-lamellar graphite), with $0.552 \%$ as average, while white (carbidic, no graphite) cast iron (WI) has appropriate values, such as $0.465 \%$ as average. The expansion at the end of solidification $\left[\left(\varepsilon_{\mathrm{di}}\right)_{\mathrm{TES}}\right]$ is only $6 \%$ lower compared to the maximum level for graphitic grey and ductile irons, while for carbidic (white) cast iron, it decreased more than 50\% because of matrix contraction (Fig.14a).

Considering $\left(\varepsilon_{\mathrm{di}}\right)_{\mathrm{gr}}=\left(\varepsilon_{\mathrm{di}}\right)_{\max }-\left(\varepsilon_{\mathrm{di}}\right)_{\mathrm{TSEF}}$ as contribution of separated graphite on the casting expansion during solidification, not only is there visible difference between non-graphite cast iron (WI) and graphitic cast irons (GI and DI), but also the graphite morphology has a noticeable effect: $0.596 \%$ expansion for DI versus $0.109 \%$ for GI. Nodular graphite led to 5 times higher values for graphitic expansion than grey iron, and, consequently, also led to higher maximum values of casting expansion. As a result of graphite formation and casting volume increasing, a graphitic force applies on the mould walls, which is favourable for contraction cavities (shrinkage, microshrinkage) formation and deteriorates the casting soundness.

Figure 14(b) shows that the increasing of the graphitic expansion $\left[\left(\varepsilon_{\mathrm{di}}\right)_{\mathrm{gr}}\right]$ of ductile iron comparing to grey iron leads to the increasing of the value of open shrinkage (Sh, $\left.\mathrm{cm}^{3} \cdot \mathrm{kg}^{-1}\right)$ and, consequently, the decreasing of the density of castings $\left(\rho, \mathrm{kg} \cdot \mathrm{cm}^{-3}\right)$ obtained in resin sand mould cast samples. The resin sand mould test samples $(50 \mathrm{~mm} \times 50$ $\mathrm{mm}$ section, $80 \mathrm{~mm}$ length, $1500 \mathrm{~g}$ weight) were subjected to the open shrinkage cavity volume measurement, using water as the penetration liquid, and the obtained shrinkage volume $\left(\mathrm{cm}^{3}\right)$ is related to the real weight of each casting. The average value of open shrinkage increases from 1.99 $\mathrm{cm}^{3} \cdot \mathrm{kg}^{-1}$ (GI) to $4.33 \mathrm{~cm}^{3} \cdot \mathrm{kg}^{-1}$ (DI). To consider all of the types of shrinkage and micro-shrinkage formation, not only at the surface but also in the body of casting, the density of the casting was also evaluated: higher graphite expansion
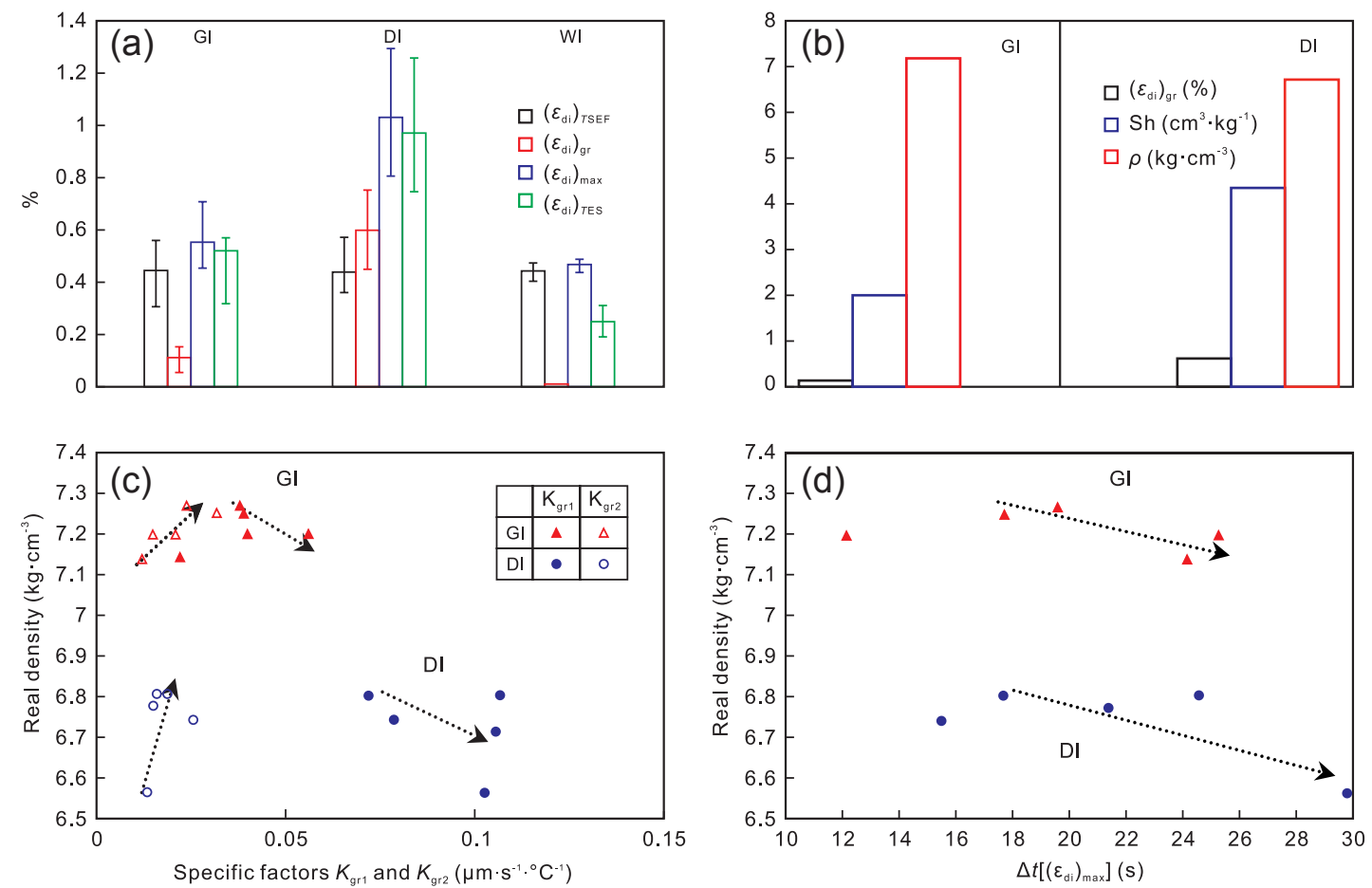

Fig. 14: Values for $\left[\left(\varepsilon_{\mathrm{di}}\right)_{\mathrm{TSEF}}\right],\left[\left(\varepsilon_{\mathrm{di}}\right)_{\max }\right],\left[\left(\varepsilon_{\mathrm{di}}\right)_{\mathrm{gr}}\right]$ and [( $\left.\left.\varepsilon_{\mathrm{di}}\right)_{\mathrm{TES}}\right]$ parameters $(\mathrm{a})$, the graphitic expansion $\left(\varepsilon_{\mathrm{di}}\right)_{\mathrm{gr}}-$ open shrinkage $\mathrm{Sh}-$ real density $\rho$ relationship (b), and the influence of the specific factors $K_{\mathrm{gr} 1}$ and $K_{\mathrm{gr} 2}(\mathrm{c})$ and the maximum expansion landing time $\Delta t\left[\left(\varepsilon_{\mathrm{di}}\right)_{\max }\right]$ (d) on the real density of cast irons samples (Program $\mathrm{V}$ ) 
resulted in a lower casting density, with a visible difference between grey cast iron and ductile cast iron ( 7.18 versus 6.73 $\mathrm{kg} \cdot \mathrm{cm}^{-3}$ as average).

A deeper analysis on the expansion/contraction curves in connection with the simultaneously obtained cooling curves (Fig. 4) leads to detailed observations on the difference of behaviour between grey and ductile cast irons. More data were presented in Refs. [32-33]. As can be seen in Fig. 12, the expansion curve of ductile iron is more accelerated comparing to the curve of grey iron up to the reaching of maximum level $\left[\left(\varepsilon_{\mathrm{di}}\right)_{\max }\right]$, while the deceleration after this moment till to the end of solidification, despite the fact that the difference remains at the same manner, is less visible.

New parameters are introduced to define the acceleration rate of the graphite expansion up to the maximum level $\left(K_{\mathrm{gr} 1}\right)$ and its deceleration to the end of solidification $\left(K_{\mathrm{gr} 2}\right)$ by the difference in expansion $\left(\Delta \varepsilon_{\mathrm{di}}\right)$ values in decreasing temperature $(\Delta T)$ and increasing time $(\Delta t)^{[32,33]}$. Equations $(1-3)$ present calculus of these parameters, including data defined by Fig. 4 :

$$
\begin{aligned}
& K_{\mathrm{gr}}=\Delta \varepsilon_{\mathrm{di}} /(\Delta T \times \Delta t), \mu \mathrm{m} \cdot \mathrm{s}^{-1} \cdot{ }^{\circ} \mathrm{C}^{-1} \\
& K_{\mathrm{gr} 1}=\left(\Delta \varepsilon_{\mathrm{di}}\right)_{(\mathrm{Kgr} 1)} /\left(\Delta T_{(\mathrm{Kgrl})} \times \Delta t_{(\mathrm{Kgr} 1)}\right)=\left[\left(\varepsilon_{\mathrm{di}}\right)_{\max }-\left(\varepsilon_{\mathrm{di}}\right)_{\mathrm{TSEF}}\right] / \\
&\left\{T_{\mathrm{SEF}}-T\left[\left(\varepsilon_{\mathrm{di}}\right)_{\max }\right]\right\} \times\left\{t\left[\left(\varepsilon_{\mathrm{di}}\right)_{\max }\right]-t\left(T_{\mathrm{ESF}}\right)\right\} \\
& K_{\mathrm{gr} 2}=\Delta\left(\varepsilon_{\mathrm{di}}\right)_{(\mathrm{Kgr} 2)} /\left(\Delta T_{(\mathrm{Kgr} 2)} \times \Delta t_{(\mathrm{Kgr} 2)}\right)=\left[\left(\varepsilon_{\mathrm{di}}\right)_{\max }-\left(\varepsilon_{\mathrm{di}}\right)_{\mathrm{TES}}\right] / \\
&\left\{T\left[\left(\varepsilon_{\mathrm{di}}\right)_{\max }\right]-T_{\mathrm{ES}}\right\} \times\left\{t_{(\mathrm{TES})}-t\left[\left(\varepsilon_{\mathrm{di}}\right)_{\max }\right]\right\}
\end{aligned}
$$

where $\left(\varepsilon_{\mathrm{di}}\right)_{(K \mathrm{grl})}$ is the increase of the expansion from the start of eutectic freezing $\left(T_{\mathrm{SEF}}\right)$ to the point of maximum expansion, while $\Delta\left(\varepsilon_{\mathrm{di}}\right)_{(\mathrm{Kgr} 2)}$ is the decrease of the expansion up to the end of solidification $\left(T_{\mathrm{ES}}\right)$, in $\% ; K_{\mathrm{grl}}$ is the acceleration rate of graphitic expansion between the start of eutectic freezing up to the maximum level, while $K_{\mathrm{gr} 2}$ is the deceleration rate to the end of solidification, in $\mu \mathrm{m} \cdot \mathrm{s}^{-1} \cdot{ }^{\circ} \mathrm{C}^{-1} ;\left(\varepsilon_{\mathrm{di}}\right)_{\mathrm{TSEF}},\left(\varepsilon_{\mathrm{di}}\right)_{\max }$ and $\left(\varepsilon_{\mathrm{di}}\right)_{\mathrm{TES}}$ are the values of expansion at the temperatures at the start of eutectic freezing, reaching the maximum expansion level, and at the end of solidification, respectively, in $\mu \mathrm{m} ; T_{\mathrm{SEF}}, T\left[\left(\varepsilon_{\mathrm{di}}\right)_{\max }\right]$ and $T_{\mathrm{ES}}$ are the temperatures at the start of eutectic freezing, reaching the maximum expansion level, and at the end of solidification, respectively, in ${ }^{\circ} \mathrm{C} ; t_{\text {(TSEF) }}, t\left[\left(\varepsilon_{\mathrm{di}}\right)_{\max }\right]$ and $t_{\text {(TES) }}$ are the times when the start of eutectic freezing is noted, at the maximum expansion

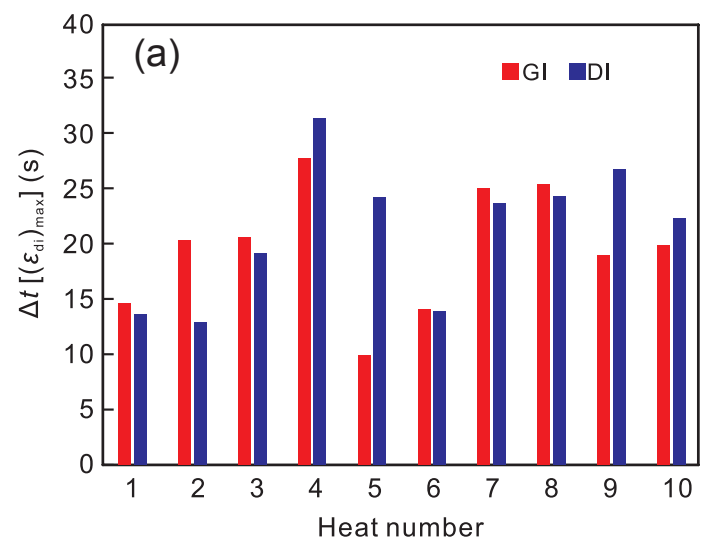

level, and at the end of solidification, respectively, in seconds.

Nodular graphite leads to the $\left(K_{\mathrm{grl}}\right)$ being 2.5 times higher, compared to GI, whereas only a slight difference is observed between GI and DI for $K_{\mathrm{gr} 2}$ (Fig. 14c). Increasing of the acceleration rate of the graphitic expansion up to the maximum level $\left(K_{\mathrm{grl}}\right)$ leads to the decreasing of the casting's density due to the presence of contraction defects. In contrast, the higher the deceleration to the end of solidification $\left(K_{\mathrm{gr} 2}\right)$, the higher the density for both cast irons. Solidification evolution during the maximum expansion landing process could also influence the soundness of iron castings. Increasing the time of the expansion at the maximum level $\Delta t\left[\left(\varepsilon_{\mathrm{di}}\right)_{\max }\right]$ (defined by Fig. 15) favours the shrinkage formation, as a result, increasing the graphitic force on the mould walls, and, consequently, decreasing the measured density of castings (Fig. 14d).

More information can be obtained if Fig. 15 is analyzed in more detail by comparing the grey and ductile cast irons as follows:

(a) The maximum initial expansion plateau length is, average of ten samples, about $8 \%$ higher for ductile cast iron than grey cast iron [Fig.16(b)] despite a very contrary position of the two irons regarding this parameter as individual heats [Fig. 16(a)].

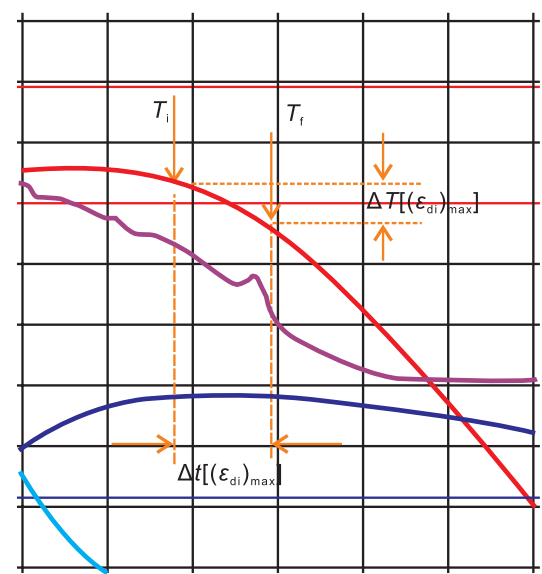

Fig. 15: Schedule for maximum expansion duration [ $\Delta t\left[\left(\varepsilon_{\mathrm{di}}\right)_{\max }\right]$ definition: $T_{\mathrm{i}}-$ the temperature on the beginning of $\left(\varepsilon_{\mathrm{di}}\right)_{\max }$ plateau; $T_{\mathrm{f}}$ - the temperature on the end of $\left(\varepsilon_{\mathrm{di}}\right)_{\max }$ plateau; $\left.\Delta T\left(\varepsilon_{\mathrm{di}}\right)_{\max }\right]$ - the temperature decreasing along the maximum $\left(\varepsilon_{\mathrm{di}}\right)_{\max }$ expansion plateau

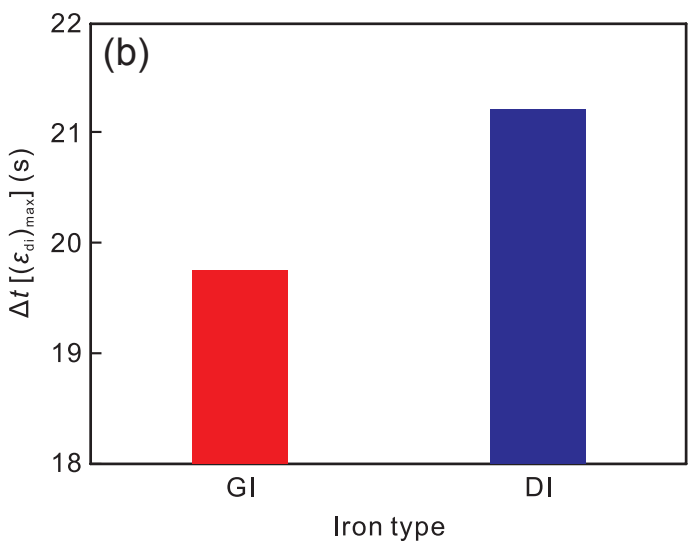

Fig. 16: Maximum initial expansion plateau duration $\Delta t\left[\left(\varepsilon_{\mathrm{di}}\right)_{\max }\right]$ for grey $[\mathrm{Gl}]$ and ductile [DI] cast irons: (a) ten samples for each iron; (b) average of ten samples (Program V) 
As can be seen from Fig.16(a), in six from ten cases, grey cast iron has a longer plateau than ductile cast iron, while in four cases, ductile iron has a much longer plateau than grey cast iron. This behaviour can be explained by the lower growth rate of nodular graphite compared with lamellar graphite; the graphite nodules are supplied by carbon diffusion through the austenite shell while lamellar graphite is directly supplied by carbon diffusion from the iron melt. The presence of vermicular graphite in the ductile cast iron structure can radically change the positions of the two types of cast iron because the vermicular graphite is closer to the lamellar form than the nodular one.

(b) The temperature decreasing along the maximum initial expansion plateau is 2.2 times higher for ductile cast iron than for grey cast iron, despite a small difference of plateau length (Fig. 17b). In this case, the difference is very clear for all samples (Fig. 17a)

(c) If the two parameters are combined as a new parameter defined by the temperature decreasing rate, $K\left[\left(\varepsilon_{\mathrm{di}}\right)_{\max }\right]=T\left[\left(\varepsilon_{\mathrm{di}}\right)\right.$ $\left.{ }_{\max }\right] / t\left[\left(\varepsilon_{\mathrm{di}}\right)_{\max }\right]\left({ }^{\circ} \mathrm{C} \cdot \mathrm{s}^{-1}\right)$ as shown in Fig. 18 , on the same plateau length, the cooling rate, that is, the solidification rate along the expansion plateau, is two times higher for ductile compared to grey cast iron. This can be explained by the different solidification models of the two cast irons: volume solidification for ductile cast iron and successive evolution of the solidification front for grey cast iron. The solid skeleton created during ductile iron casting solidification favours an easier extraction heat from the liquid centre of casting ${ }^{[38]}$. This could be another explanation of the higher tendency of ductile cast iron to form micro shrinkage defects.
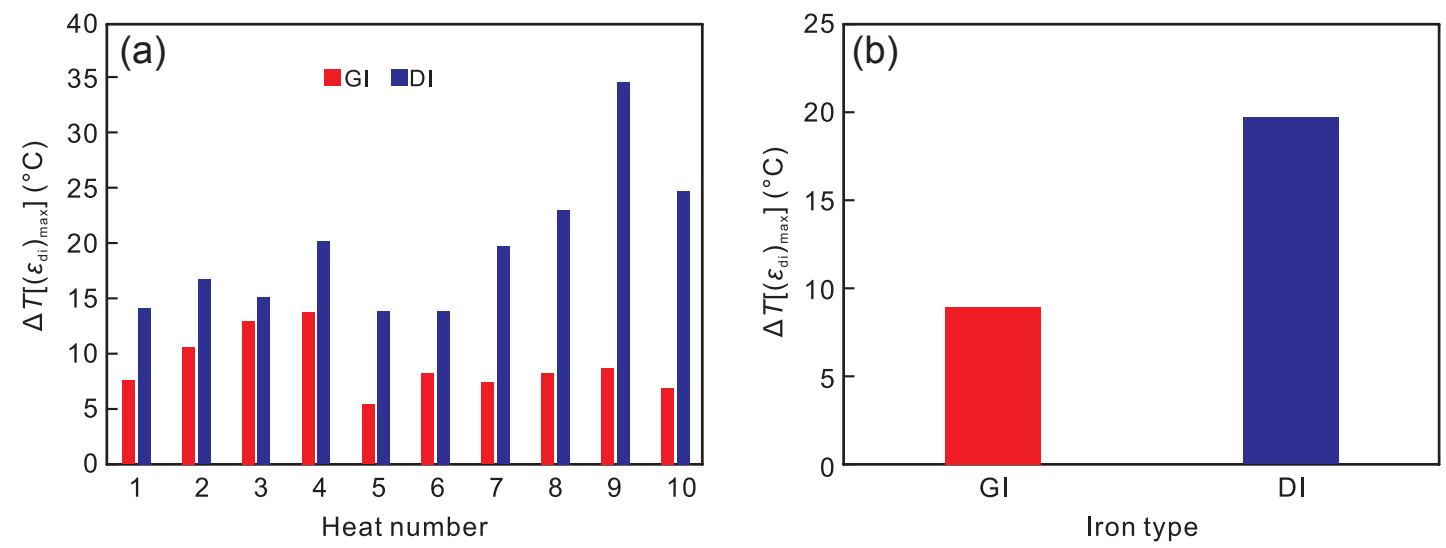

Fig. 17: Temperature decreasing along the maximum expansion plateau $\left.\Delta \pi\left(\varepsilon_{\mathrm{di}}\right)_{\max }\right]$ for grey (GI) and ductile (DI) cast irons: (a) ten samples for each iron; (b) average of ten samples (Program V)
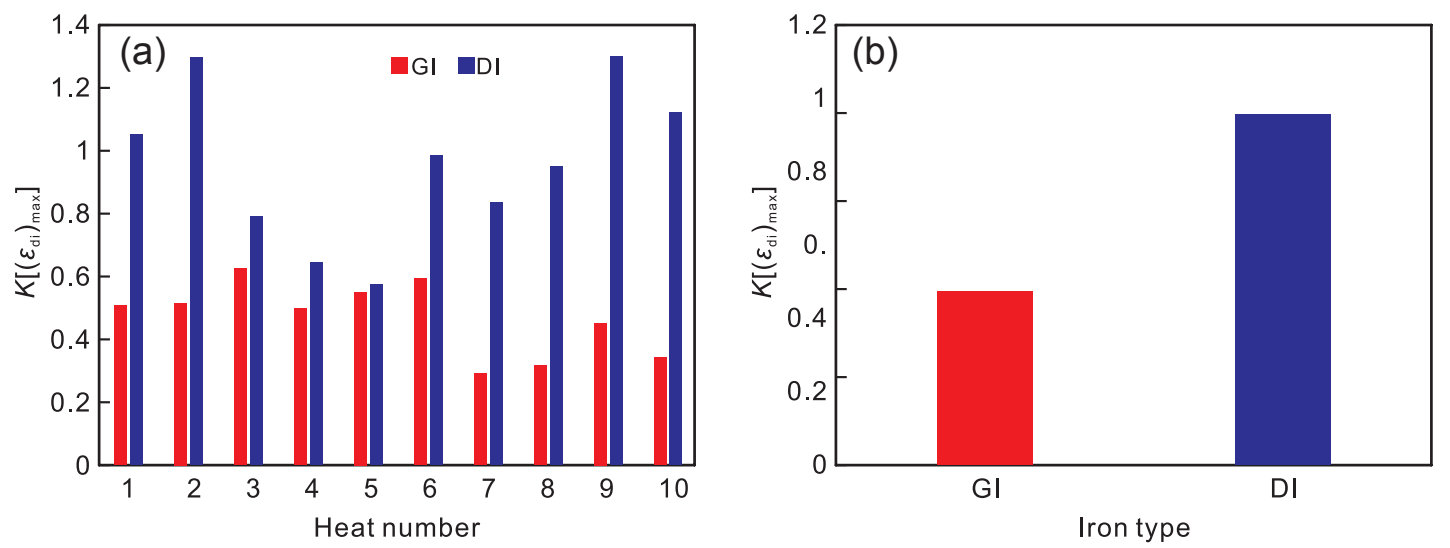

Fig. 18: Temperature decreasing rate $K\left[\left(\varepsilon_{\mathrm{di}}\right)_{\max }\right]$ along the maximum expansion plateau for grey (GI) and ductile (DI) cast irons: (a) ten samples for each iron; (b) average of the ten samples (Program V)

For the same behaviour of iron castings up to the start of eutectic freezing as their size variation, graphitization process appears to be a very important factor to favour the shrinkage and micro-shrinkage formation during solidification. First of all, the level of graphitizing force applied to the mould wall is important: higher force results in higher graphite amount, especially for nodular graphite formation. Also important is the moment when the graphitic force is recorded: at the beginning of eutectic reaction, which favours shrinkage formation, or at the last part of eutectic reaction, which does not favour shrinkage formation, respectively.

It appears that from the metallurgical treatment point of view, favourable conditions to limit shrinkage and micro-shrinkage sensitiveness are as follows: to promote only a few graphite nodules at the beginning of solidification (usually at large size), but a high graphite precipitation at the end of solidification (usually as higher nodule count, lower size). In this way, the limited increased volume due to the limited graphite formation 
in the first part of solidification will determine a limited force applied to the mould walls, generally favourable for cavities formation. If graphite formation will be promoted at the end of solidification, the graphite force will push the last liquid to the previous formed contraction cavities and fill them (higher casting soundness will result).

The obtained results as a role of graphitic expansion and especially as its variation on the entire solidification stage (end versus beginning of solidification) could explain the previous results on reduced shrinkage tendency in ductile iron castings when using $\mathrm{Ce}, \mathrm{Ca}, \mathrm{S}, \mathrm{O}-\mathrm{FeSi}$ inoculation (Fig. 8) or $\mathrm{La}-\mathrm{MgFeSi}$ nodularisation treatment ${ }^{[11,17,20,26,34,36]}$. This is attributed to a bimodal or skewed nodule size distribution (fewer large nodules formed at the start of solidification and a higher number of much smaller nodules formed later, towards the end of solidification).

\section{Summaries}

(1) Simultaneous evaluation of solidification cooling and contraction curves are considered to identify the most representative parameters useful to foresee the structure characteristics and possible contraction defects of grey, ductile and white cast irons. By positioning the lowest $\left(T_{\mathrm{EU}}\right)$ and highest $\left(T_{\mathrm{ER}}\right)$ eutectic reaction temperatures and the temperature of the end of solidification $\left(T_{\mathrm{ES}}\right)$ comparing to the stable (graphitic) $\left(T_{\mathrm{st}}\right)$ and metastable (carbidic) $\left(T_{\mathrm{mst}}\right)$ eutectic temperatures, the representative solidification undercooling degrees are obtained, which were found to be important parameters in solidification control of the cast irons.

(2) Three important events are identified on the expansion/ contraction curves: $\left(\varepsilon_{\mathrm{di}}\right)_{\mathrm{TSEF}}$-expansion up to the start of eutectic freezing; $\left(\varepsilon_{\mathrm{di}}\right)_{\max }$-maximum expansion level, positioned between the highest eutectic temperature $\left(T_{\mathrm{ER}}\right)$ and the temperature of the end of solidification $\left(T_{\mathrm{ES}}\right) ;\left(\varepsilon_{\mathrm{di}}\right)_{\mathrm{TES}}$-expansion at the end of solidification. The difference between $\left(\varepsilon_{\mathrm{di}}\right)_{\max }$ and $\left(\varepsilon_{\mathrm{di}}\right)_{\mathrm{TSEF}}$ is attributed to the graphite formation, $\left(\varepsilon_{\mathrm{di}}\right)_{\mathrm{gr}}$.

(3) It is found that an expansion starts immediately at the moment of the iron melt pouring up to the start of the eutectic graphitization, $\left(\varepsilon_{\mathrm{di}}\right)_{\mathrm{TSEF}}$, at the same level for all of the tested cast irons, due to the ferrostatic pressure, silica sand mould expansion, mould movement, etc.

(4) Nodular graphite leads to 2-5 times higher values for graphitic expansion, comparing to lamellar graphite, and, consequently, leads to the higher maximum values of casting expansion. A graphitic force resulted by the expansion, applied on the mould walls, is favourable for contraction cavities (shrinkage, micro-shrinkage) formation and deterioration of the casting soundness.

(5) New parameters are introduced to define the acceleration rate of the graphite expansion up to the maximum level $\left(K_{\mathrm{gr} 1}\right)$ and its deceleration to the end of solidification $\left(K_{\mathrm{gr} 2}\right)$, by the difference in expansion $\left(\Delta \varepsilon_{\mathrm{di}}\right)$ values in decreasing temperature $(\Delta T)$ and increasing time $(\Delta t)$. Nodular graphite leads to the $\left(K_{\text {grl }}\right)$ being 2.5 times higher, compared to GI, whereas only a slight difference is observed between GI and DI for the $K_{\mathrm{gr} 2}$. Increasing the acceleration rate of the graphitic expansion up to the maximum level $\left(K_{\mathrm{grr}}\right)$ leads to the decreasing of real density due to the presence of contraction defects.

(6) Increasing the time of the expansion at the maximum level $\Delta t\left[\left(\varepsilon_{\mathrm{di}}\right)_{\max }\right]$ favours the shrinkage formation, as a result of increasing the graphitic force on the mould walls, and consequently, decreasing the measured density of castings.

(7) The maximum initial expansion plateau length is about $8 \%$ higher for DI than for GI, while the temperature decreasing along the maximum initial expansion plateau is 2.2 times higher for DI than for GI, despite of a small difference in plateau length.

(8) Graphitization process appears to be a very important factor to favour the shrinkage and micro-shrinkage formation during solidification. Higher graphite amount leads to higher graphitizing force applied to the mould wall, especially for nodular graphite formation, favouring the shrinkage occurrence at the beginning of eutectic reaction and de-favouring it, at the last part of eutectic reaction.

(9) Consequently, strong graphitization process promotion at the end of eutectic reaction solidification, by specific metallurgical treatments, such as inoculation with special formulated alloys [Ca, Ce, S, O-FeSi, La-bearung FeSi alloys] favours the castings soundness.

(10) Less rigid green sand moulds encourage the formation of contraction defects, not only because of the high initial expansion values $\left(\varepsilon_{\mathrm{di}}\right)_{\max }$, but also because of the increased solidification undercooling.

\section{Acknowledgements}

The work has been funded by the Operational Programme Human Capital of the Ministry of European Funds through the Financial Agreement 51668/09.07.2019, SMIS code 124705.

\section{References}

[1] Sillen R V. Novacast Technologies, 2006, www.novacast.se.

[2] Stefanescu $D$ M. Thermal analysis-theory and applications in metalcasting. Int. J. Metalcasting, 2015, 9(1): 7-22.

[3] Sparkman D. Microstructure by thermal analysis. AFS Trans., 2011, 119: 413-419.

[4] Chisamera M, Riposan I, Stan S, et al. Thermal analysis control of in-mould and ladle inoculated grey cast irons. China Foundry, 2009, 6(2): 145-151.

[5] Stan S, Chisamera M, Riposan I, et al. Applications of thermal analysis to monitor the quality of hypoeutectic cast irons during solidification in sand and metal moulds. J. Therm. Anal. Calorim., 2012, 110(3): 1185-1192.

[6] Riposan I, Chisamera M, Stan S. Application of cooling curve analysis in solidification pattern and structure control of grey cast irons. J. Therm. Anal. Calorim., 2018, 132(2): 10171028.

[7] Kanno T, Iwami Y, Kang I. Prediction of graphite nodule count and shrinkage tendency in ductile cast iron with 1 cup thermal analysis. Int. J. Metalcasting, 2017, 11(1): 94-100. 
[8] Kanno T, Fukuda Y, Kang I, et al. Prediction of chilling tendency in cast iron using three cups thermal analysis system. J. JFS, 1998, 70: 773-778.

[9] Kanno T, Nakae H. Prediction of graphite types and mechanical properties in cast iron using three cups thermal analysis. J. JFS, 2000, 72: 175-180.

[10] Klancnik U, Habjan J, Klancnik G, et al. Thermal analysis of indefinite chill cast iron modified with ferrovanadium and ferrotungsten. J. Therm. Anal. Calorim., 2017, 127: 71-78.

[11] Riposan I, Skaland T. Modification and inoculation of cast iron. In: D. M. Stefanescu, Volume Editor, Cast Iron Science and Technology Handbook, American Society of Materials, 2017: 160-176.

[12] Riposan I, Chisamera M, Stan S. New developments in high quality grey cast irons. China Foundry, 2014, 11(4): 351-364.

[13] Winter B P, Ostrom T R, Hartman D J, et al. Mold dilatation and Volumetric shrinkage of white, gray and ductile cast irons. AFS Trans., 1984, 92: 551-560.

[14] Bates C E, Oliver G L, McSwain R H. Volumetric changes during freezing of ductile cast iron. AFS Trans., 1977, 85: 289-298.

[15] Wallace J F, Samal P K, Voss J D. Factors influencing a shrinkage cavity formation in ductile iron. AFS Trans., 1984, 92: 765-784.

[16] Svidro P, Dioszegi A. On problems of volume change measurements in lamellar cast iron. Int. J. Cast Met. Res., 2014 27(1): 26-37.

[17] White D. Avoiding shrinkage defects in ductile iron. In: Proceedings of the 115th AFS Casting Congress, Schaumburg, II, USA, April 2011, Paper No. 11-141.

[18] Li W Z, Liu B C, Li J R. Shrinkage behaviour of spheroidal graphite cast iron in green and dry sand molds for the benchmarking of solidification simulation. J. Mater. Sci. Technol., 2001, 17(6): 610-614.

[19] Stefanescu D M. Computer simulation of shrinkage related defects in metal castings - a review. Int. J. Cast Met. Res. 2005, 18(3): 129-143.

[20] Skaland T. Ductile iron shrinkage control through graphite nucleation and growth. Int. J. Cast Met. Res., 2003, 16(1-3): 1116.

[21] Ohnaka I, Iwane J, Yasuda H, et al. Prediction of porosity defect in spheroidal graphite iron castings. Int. J. Cast Met. Res., 2003, 16(1-3): 293-299.

[22] Regordosa A, Llorca-Isern N. Microscopic characterization of different shrinkage defects in ductile irons and their relation with composition and inoculation process. Int. J. Metalcast., 2017 11(4): 778-789.

[23] Stefanescu D M, Moran M, Boonmee S, et al. The use of combined liquid displacement and cooling curve analysis in understanding the solidification of cast irons. AFS Trans., 2012, 120: $365-374$
[24] Alonso G, Stefanescu D M, Suarez R. Understanding graphite expansion during the eutectic solidification of cast iron through combined linear displacement and thermal analysis. Int. Foundry Res., 2014, 66(4): 2-12.

[25] Tadesse A, Fredriksson H. Volume change during the solidification of grey cast iron: its relation with the microstructura variation, comparison between experimental and theoretical analysis. Int. J. Cast Met. Res., 2017, 30(3): 159-170.

[26] Riposan I, Chisamera M, Stan S, et al. Analysis of cooling and contraction curves to identify the influence of inoculants on shrinkage behavior of ductile irons. In: Proceedings of the Keith Millis Symposium on Ductile Cast Iron, Hilton Head Island, USA Oct., 2003: 125-135.

[27] Chisamera M, Riposan I, Stan S, et al. Shrinkage evaluation in ductile iron as influenced by mold media and inoculant type. Int. J. Cast Met. Res., 2011, 24(1): 28-36.

[28] Chisamera M, Riposan I, Stan S, et al. Simultaneous cooling and contraction/expansion curve analysis during ductile iron solidification. AFS Trans., 2012, 120: 375-388.

[29] Stan S, Chisamera M, Riposan I, et al. Technique incorporating cooling \& contraction/expansion analysis to illustrate shrinkage tendency in cast irons. IOP Publishing, IOP Conf. Series: Materials Science and Engineering, 2017, 209, 12017.

[30] Stan S, Chisamera M, Riposan I, et al. Integrated system of thermal/dimensional analysis for quality control of metallic melt and ductile iron casting solidification. J. Mater. Eng. Perform. 2018, 27(10): 5187-5196.

[31] Stan S, Chisamera M, Riposan I, et al. Simultaneous thermal and contraction/expansion analyses of cast iron solidification process. J. Therm. Anal. Calorim., 2019, 138(4): 2529-2540.

[32] Stan S, Chisamera M, Riposan I, et al. Integrated system of thermal/dimensional analysis for quality control of gray and ductile iron castings solidification. Int. J. Metalcasting, 2019, 13(3): 653-665.

[33] Riposan I, Stan S, Chisamera M, et al. Control of solidification pattern of cast iron by simultaneous thermal and contraction/ expansion analysis. IOP Conferences Series: Materials Science and Engineering, 2019, 529, 012016.

[34] Skaland T. A New method for chill and shrinkage control in ladle treated ductile iron. In: Proceedings of the 66th World Foundry Congress, Istanbul, Turkey, Sept. 2004: 975-987.

[35] Skaland T. A new approach to ductile iron inoculation. AFS Trans., 2001, 109, Paper 01-078.

[36] LAMET® Nodulariser-ELKEM Foundry Products Brochure, www.foundry.elkem.com (May 2007)

[37] Van Der P W. Thermal analysis in cast iron-principles and applications. Heraeus Electro-Nite Seminar, October 2000 Bucharest, Romania.

[38] Zhu P, Smith R W. Using thermal analysis to predict the microstructure of cast iron. Advanced Materials Research, 1997 (4-5): 439-444. 